Seton Hall University eRepository@Seton Hall

Seton Hall University Dissertations and Theses (ETDs)

2004

Students' Learning Styles And Their Preferences For Online Instructional Methods

Thomas John Butler

Seton Hall University

Follow this and additional works at: https://scholarship.shu.edu/dissertations

Part of the Curriculum and Instruction Commons, and the Medical Education Commons

Recommended Citation

Butler, Thomas John, "Students' Learning Styles And Their Preferences For Online Instructional Methods" (2004). Seton Hall University Dissertations and Theses (ETDs). 1456.

https://scholarship.shu.edu/dissertations/1456 


\title{
STUDENTS' LEARNING STYLES AND THEIR PREFERENCES FOR ONLINE INSTRUCTIONAL METHODS
}

\section{BY}

Thomas John Butler

\author{
Dissertation Committee
}

Dr. Genevieve Pinto-Zipp, Chair

Dr. Philip DiSalvio

Dr. Valerie Olson

Approved by the Dissertation Committee:

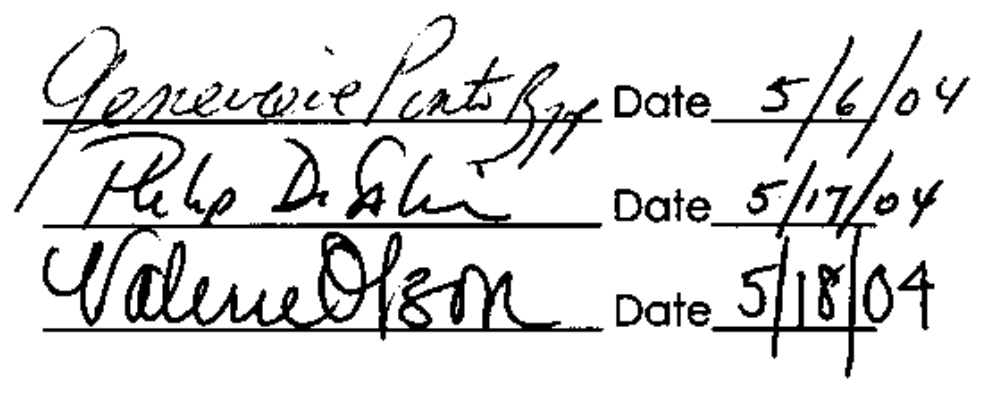

Submitted in partial fulfiltment of the requirements for the Degree of Doctor of Philosophy in Health Sciences Seton Hall University 
Copyright (ㄷ Thomas John Butler 2004 


\section{ACKNOWLEDGEMENTS}

I would like to thank my Dissertation Chair, Dr. Genevieve Pinto-Zipp for her commitment to this project and her calming words of encouragement and support when the process was stalled or not progressing to my liking.

Thanks also to the members of my Committee. To Dr. Olson for her expertise on learning styles and to Dr. DiSalvio who opened the door to SetonWorldWide which provided me with the access and the resources to complete the data collection. Without that access, this dissertation would not have been possible.

I would also like to thank Dr. Darby Ullyatt, Director of Product Development at SetonWorldWide, for the tremendous amount of assistance she provided. Her technical expertise, contacts at eCollege, and words of advice and support were invaluable.

Lastly thanks to all those fellow students, faculty and staff that I met on this journey. The friendship, collegiality and support provided by them over the past five years will not be forgotten. 


\section{DEDICATION}

This Dissertation is dedicated to the family and friends who supported my desire to return to school to earn a Doctorate. Spurred on by their wisdom of "you'll get old with it or without it," they offered words of encouragement, provided a shoulder to lean on when needed, and stood behind me all the way. To my sisters Helen and Joanne, my friend AI DeMoya, I thank you for your patience.

A special note of thanks belongs to my dear friend, Amy Ceconi. Amy was a constant source of encouragement and support as we traveled this road together. Without her, my perseverance and tenacity would have wavered. 


\section{TABLE OF CONTENTS}

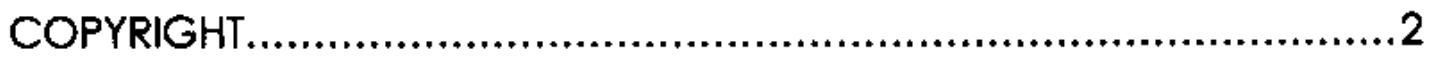

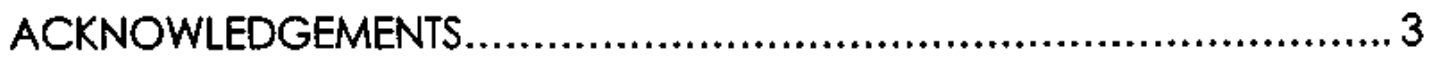

DEDICATION...................................................................... 4

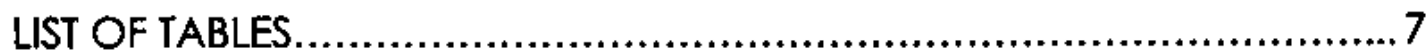

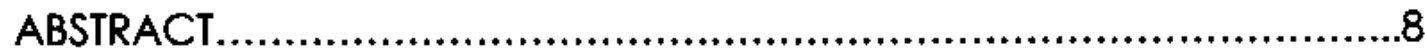

I INTRODUCTION ....................................................................... 11

Statement of the Problem..................................................11

Definition of Terms........................................................... 16

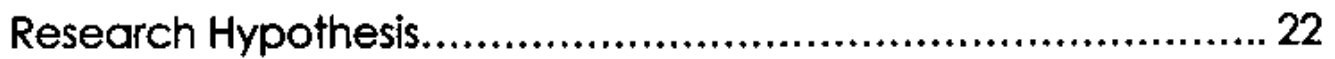

Research Questions..................................................... 23

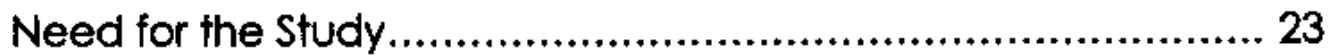

॥ REVIEW OF THE RELATED LITERATURE..................................... 26

Learning Styles Inventories............................................... 26

Application of LSIs in Traditional Education.............................36

Application of LSIs in Online Education.................................41

Online Course Design and Faculty Development.................... 48

Course Design and Learning Styles....................................... 53

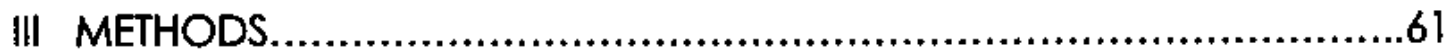

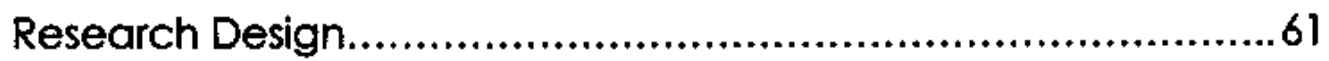

Subjects and Procedures.................................................61 61

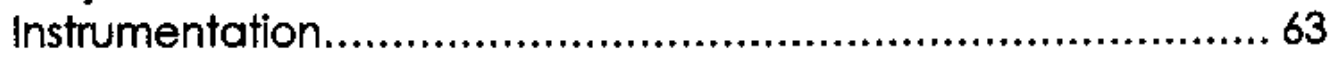

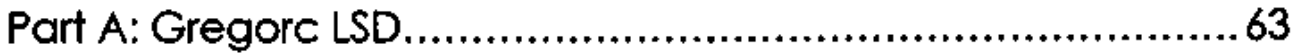

Part B: Questionnaire.................................................65

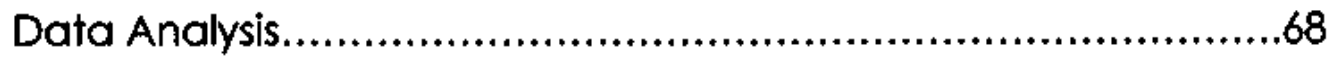

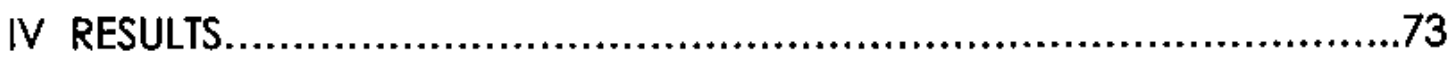

Respondent Demographics..........................................73

Online Program..........................................................

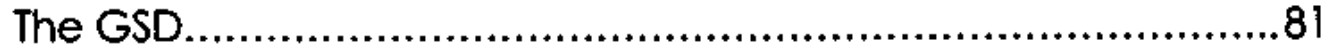

Online Instructional Methods Ratings................................. 85

Learning Styles and Methods of Online Instruction Correlations...87 


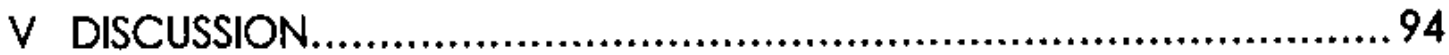

Respondent Demographics...........................................94

The Online Experience.....................................................95

The First Research Question..............................................96

Learning Styles ...........................................................96

The Second Research Question.........................................97

Preferences for Online Instructional Methods........................97

The Third Research Question.............................................99

Learning Styles and Online Instructional Methods................. 99

VI SUMMARY AND CONCLUSIONS.........................................106

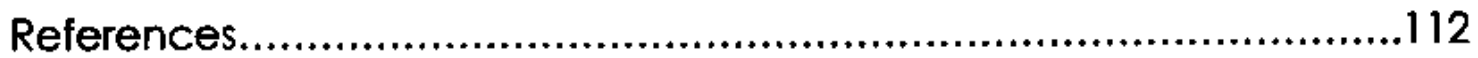

Appendices.......................................................................... 119

A. PERMISSION TO SOLICIT SETONWORLDWIDE STUDENTS...............119

B. IRB APPROVAL LETTER.............................................. 121

C. PERMISSON TO USE THE GREGORC LEARNING STYLES

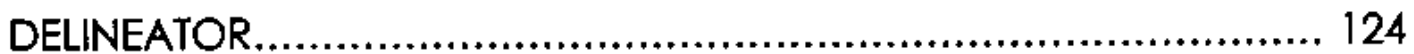

D. SOLICITATION LETTER................................................ 126

E. INFORMED CONSENT FORM .........................................128

F. SAMPLE OF THE GREGORC LEARNING STYLES DELINEATOR

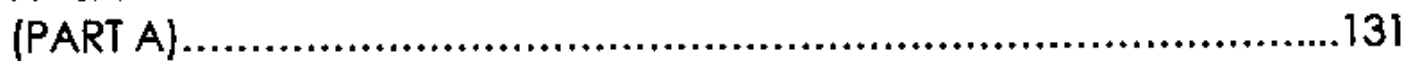

G. PILOT SURVEY OF THE SETONWORLDWIDE FACULTY..................136

H SAMPLE OF THE STUDENT SURVEY (PART B) .......................... 139 


\section{LIST OF TABLES}

1. Summary of Gregorc Learning Styles and Personality Characteristics...

2. Media, Teaching Methods and Practices...............................58

3. Instructional Activities Used by SWW Faculty............................67

4. Summary of Survey Responses..........................................69

5. Distribution of Respondents According to Degree Program.............73

6. Reasons for Enrolling in an Online Program.............................76

7. Level of Satisfaction with Online Program...............................78

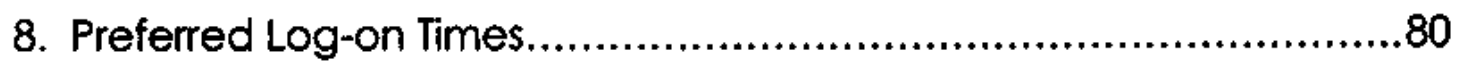

9. Comparison of Mean Scores of Learning Styles Types...................82

10. Distribution of Learning Style Types.....................................84

11. Online Instructional Methods Ratings....................................86

12. Pearson-product Moment Correlation Coefficients for Learning Styles and Online Instructional Methods...

13. Rotated Loading Factor Matrix for Six Extracted Factors.

14. Pearson-product Moment Correlation Coefficients for Learning Styles and Factors. 


\begin{abstract}
Statement of the Problem: The explosion of the number of available online courses and complete degree programs is astounding. It is predicted that the number of online courses will continue to increase as will the enrollment in these types of courses. Thus, it is incumbent upon educators to meet the unique needs of students enrolled in online education. Based upon the need to provide a meaningful learning experience in the online environment, several questions arise. First, is there a dominant learning style in students who enroll in online courses? Second, is there a preferred method of online instruction and finally, is there a relationship between learning styles and the preferred method of online instruction?

Methods: A two-part survey was administered to all graduate students enrolled in SetonWorldWide. Part A of the survey consisted of the Gregorc Learning Styles Delineator (GSD) while Part B consisted of demographic questions and a Likert scale focusing on the rating of online instructional methods. Learning styles were determined according to the procedures outlined by Gregorc (Gregorc, 1982). Descriptive and correlation statistics were calculated using SPSS statistical software. Principal component analysis reduced the constructs to six extracted factors.
\end{abstract}


Results: The subjects $(\underline{N}=96$ ) displayed various learning styles with dual learning styles $(56.2 \%)$ representing the largest group. The subjects demonstrated strong preferences for asynchronous log-ons (99\%), a high degree of interaction within the course, and also noted a high degree of satisfaction with their online programs (95\%). Convenience was the most frequent reason reported (92\%) as to why a web course was selected. There were several correlations found between learning styles and preferred methods of online instruction, which were partly attributed to the learning styles traits as described by Gregorc. However, the strong preferences for instructional activities emphasizing convenience and time management and interactivity (threaded discussions, $\underline{M}=4.41$, individual assignments, $\underline{M}=4.33$ ) seemed to supplant those that might be preferred according to learning styles. Factor analysis yielded six extracted factors that grouped strongly according to instructional preference: Online Instructional Methods (ejournal, e-reserve, mini-lectures and videos), Communication Instructional Methods (chat room and threaded discussion), Analysis Instructional Method (webliography and web-site evaluation, Visual Instructional Methods (CD-ROM use and video clips), Individual Instructional Methods (textbook readings and case studies), and Assessment instructional Methods (quizzes). Correlation analysis 
between students' learning styles scores, and the six online instructional methods factors revealed several statistically significant relationships. However, they were inconsistent with the personality traits defined by learning styles.

Conclusion: Students enrolled in online education because of the convenience. The largest percentage of students in the sample displayed a dual learning style, indicating flexibility with the method of online instruction, but favored the forms of online pedagogy of individual assignments and threaded discussions. An alternative explanation of these findings, which transcends their individual learning style, may be found in the student's personal motivation for seeking a graduate degree. 


\section{Chapter I}

INTRODUCTION

\section{Statement of The Problem}

The explosion in the availability of online courses has been as astounding as the growth in the use of the home personal computer. Virtual universities, such the University of Phoenix and Regis University, have emerged as leaders. In 1989, The University of Phoenix began offering online courses. It now boasts an enrollment of 55,000 students. Each of these two institutions has more graduate students enrolled in online courses than students with the same major enrolled in traditional courses at Harvard and Yale Universities (Jones, 2003). As a result, in order to be competitive, many colleges and universities have chosen to offer online courses. In $2001,60 \%$ of campuses in the United States offered at least one online course (Kingsley, 2002). The National Center for Educational Statistics (http://www.nces.ed.gov, 2003) estimated that $1,661,100$ students were enrolled in college level distance education in 1997 - 1998. In its most recent analysis (Walts \& Lewis, 2003), The National Center found that in the year $2000-2001,56 \%$ of all Title IVeligible two and four-year instifutions offered distance education. This encompassed $3,077,000$ students enrolled in 127,400 different courses. 
While $31 \%$ of the institutions polled reported no interest in offering distance education, $12 \%$ indicated that they would implement a distance education program in the next three years. Of those institutions currently offering distance education, $88 \%$ indicated that they would increase the number of course offerings in the next three years. It is also predicted that within 20 years, online classes with as many as 1,000 students will replace traditional classroom courses (Carnevale, 1999).

There are a number of institutions that have elected to offer education online as an alternative to education in the traditional classroom setting. The SUNY Learning Network $(S L N)$, which administers all online courses for the State University of New York System, has experienced a phenomenal growth pattern. At the inception of the SLN program, eight courses were offered at several institutions in the 1995-1996 academic year whereas over 1500 courses were offered at 53 SUNY institutions in the 2000-2001 academic year. In subsequent years, these numbers have increased dramatically with SLN predicting to surpass 20,000 students for the 2003-2004 academic year (http://www.suny.SLN.edu, 2002).

Seton Hall University (SHU) is another example of an institution that offers online classes. Through SetonWorldWide (SWW), six complete 
online graduate programs and one undergraduate degree program are offered. These courses enroll over 300 students (http://www.setonworldwide.net, 2002). In a pattern similar to SLN, SHU's online offerings have continued to grow and expand.

These institutions have provided various rationales for offering online courses with corresponding pedagogical methodologies, which have emerged to insure that the same level of learning is achieved in online courses as in traditional classroom courses. Initially, the posting of course syllabi, electronic references, and assignments or questions constituted online course pedagogy. However, the extent and quality of the instructional strategies, still the purview of the instructor, have expanded to include, but are not limited to, audio and video clips, case studies, and online research (SLN, 2000).

In addition, an entirely new generation of learners has emerged. These learners, in many instances, possess enhanced computer and technology skills, and demonstrate higher levels of skill in comparison to many of the instructors. Surveying 1406 SLN students in 1999. Swann et al. (2000) found that $88 \%$ of the students surveyed reported average to high computer skills, yet $73 \%$ acknowledged that this was the first online course taken. Clearly, instructors need to adapt their teaching methodologies to encompass the educational needs of this current 
generation of learners. Interestingly, those students who enroll in online courses include a mixture of traditional and non-traditional college students. In the same study (Swan ef al, 2000), student demographics indicated that $90 \%$ of the students were between 16 and 55 years of age, $67 \%$ were female, $52 \%$ worked full-time and $48 \%$ lived less than 30 minutes away from campus. Thitty-seven percent claimed conflicts with personal schedule as the reason for enrolling in an online course. Other reasons were family responsibilities (15\%), course not offered on campus (13\%), and lack of transportation (12\%). Only $10 \%$ indicated an interest in technology as the chief reason for enrolling in a web course (Swan, ef al., 2000). Therefore the offering of online courses, which can be viewed as only a matter of convenience or time management, or even perhaps financially advantageous to the institution, is now subject to scrutiny and an emerging body of literature has accumulated. The research regarding online learning includes course construction and management, students' level of computer skills, instructional methods, comparisons of traditional and online courses. (SLN, 2000; Swan et al., 2000).

The goal of education is to insure that students learn. The course instructor provides students with the goals and objectives for each course. Whether learning occurs in the traditional classroom setting or 
in the online environment is a major concern for all educators. Therefore, in order to improve pedagogy and insure that learning occurs, the nature of the learning process has been studied. This analysis of learning has led psychological researchers to the development of several instruments for assessing personality traits or learning styles. A learning style is the manner in which an individual gains, processes, and stores information (Seidel \& England, 1997). These tools include the Kolb Learning Styles Inventory (Kolb, 1976), the Canfield Learning Styles Inventory (Canfield \& Lafferty, 1974), and the Gregorc Learning Styles Inventory (Gregorc, 1982) and the GrashaReichmann Learning Styles Scale (Grasha, 1996). The Myers-Briggs Personality Type Indicator, which assesses personality traits rather than learning styles, is another instrument commonly used in educational research (Myers \& McCaulley, 1985). For more researched than the nature of online education, the study and usefulness of assessing learning styles in traditional classroom pedagogy has had a constant presence in the literature. Gregorc and Butler (1984) observed that individuals "appear to learn best when teaching styles and technologies fit our learning styles" (p. 27). To date, learning style assessment toois have been used to evaluate, predict, and improve learning outcomes in a variety of academic programs such as accounting (Eide, Geiger, \& 
Schwartz, 2001), liberal arts (Seidel \& England, 1997), dental students (Hendricson, Berlocher, \& Herbert, 1987) as well as in other health professions (Katz \& Heimann, 1991; Olson \& Scanlan, 2002) and in specific courses such as anatomy and physiology (Harasym, Leong, Lucier, \& Lorscheider, 1995; Harasym, Leong, Juschka, Lucier, \& Lorscheider, 1995).

It is incumbent upon educators to pose the same questions to the online learning experience that were once posed regarding classroom learning experience. For example, what activities are best suited for the online environment? Is teaching done in the same manner as in the traditional "walled-in" classroom? Do students enrolled in online courses learn in the same manner as those in the traditional classroom? Do students' learning styles impact online learning? Since the study and use of learning styles have been supported as tools used to assess and assist all learners, can the use of learning styles enhance the online learning experience?

\section{Definition of Terms}

In the discussion of online learning, the following terms are to be operationally defined: learning style, critical thinking, benchmark, online course, and online instructional method. The individual online 
instructional methods have also given rise to a new vocabulary. These must also be defined in order to provide clarity and standardization.

\section{Ipsative scale}

An ipsative scale is an assessment that uses the self as a reference point and the yardstick by which comparisons are made. Thus, personal belief, ethics and behaviors are incorporated into the measurement. (Dictionary of Student Outcome Assessment, 2003).

\section{Learning style}

Learning style is the method by which an individual gains, processes, and stores information (Gregorc, 1982; Butler 1988).

Critical thinking

Critical thinking includes thinking that is reasonable and reflective and focused on what to believe or do (Norris \& Ennis, 1989). Four skill areas for critical thinking are clarification, assessing evidence, making and judging inferences, and using appropriate strategies and tactics (Bullen, 1998).

\section{Benchmark}

A standard by which something can be measured or judged is a benchmark. 


\section{Online course}

For the purpose of this study, an online course is a course that is offered on the World Wide Web by a nationally accredited institution of higher learning. These courses are also referred to as a web-based course.

\section{Course platform}

The software used for the presentation and management of all course materials including instructional methods. Common platforms are WebCT, Blackboard, and eCollege.

Online instructional method

Online instructional method is defined as any learning activities that are interactive and require student participation. These include, but are not limited to, threaded discussions, current themes or events chat rooms, online research, online case studies, and participation in a mandated number of e-mail or online contacts per week. Posting of a syllabus or reading assignments are not included.

Specific online instructional methods are defined as:

\section{Asynchronous environment}

This course management method permits students to log-on and submit work based on the timeframes established in the syllabus, but they are not required to log-on at a set time (SLN, 2000). 


\section{Synchronous environment}

This course management method requires the students and or the instructor to log-on at a particular set time in order to participate in a simultaneous activity, such as the discussion of an assigned topic (SLN, $2000)$.

\section{E-journal}

Similar to a learning journal, the student maintains an electronic log of all learning activities.

\section{E-reserve}

E-reserve is a method in which the instructor places journal articles, excerpts from textbooks and other printed materials directly online. Students can download or print the articles and, therefore, do not need to go to the campus library in order to obtain and read an assigned article.

\section{Individual assignment}

This learning activity, which is established by the instructor, is completed and submitted by each individual student. The assignment may be submitted directly to the instructor, or to the class for discussion or critique. 


\section{Group assignment}

Students are either assigned to a group by the instructor or students self-select a group, and work in the group to complete an assigned project. The students are responsible to communicate within the group, assign tasks, and establish time frames that adhere to the criteria established by the instructor.

\section{Online multimedia resource center}

This is an established web site that provides the students and instructors with links to web resources. Links are discipline-specific. An example of a free online multimedia resource center is the Multimedia Educational Resource Center for Online Teaching (MERLOT).

\section{Threaded discussion}

Students respond to and discuss a critical issue or current theme posted by the instructor. Students respond to postings of their classmates also, thus establishing a continuing dialogue or thread. Typically, responses must be supported with references and not simple concurring statements.

\section{Self-assessment quiz}

Self-assessment quiz is an objective assessment that allow students to answer quiz questions related to the subject matter. The 
software grades the quiz and provides students with immediate feedback for incorrect answers.

\section{Supplemental CD-ROM}

Most publishers provide a supplemental CD-ROM with the textbook that contains a myriad of learning activities. Some of these activities may be incorporated as part of the course requirements.

\section{Video clip}

A video clip is a short piece of electronic video. Instructors may provide a link to a video clip and require the students to complete an assignment based on that clip, or the clip may be embedded into the course. The instructor may also ask a student to create and submit a video clip as an assignment, which may be used to evaluate student performance, such as in a counseling course

\section{Webliography}

Students may be required to research, evaluate, and post web site addresses for online resources and references, a compilation known as a webliography. A webliography may also serve as an additional resource for students' use. 


\section{Research Hypothesis}

Before the advent of online education, Gregorc and Butler (1984) observed that "the methods of instruction and types of technology are accepted differently by individuals and actually make different demands on their minds" (p. 27). Gregorc contends that instructional methods imposed on students engaged in the learning experience are reflected in their individual learning styles, or the manner in which they receive and process information (Gregorc, 1984). This concept may be extended to include learning accomplished through courses taught online. One may conclude that the various online instructional methods will be processed and interpreted differently by the students engaged in online learning. Consequently, each individual student will use the online environment and the imposed instructional methodologies according to the student's learning style.

The research hypothesis is: Students enrolled in online education reveal predominant learning styles and when grouped by learning styles, students enrolled in graduate online courses differ in their preferences for online instructional methods. 
Research Questions

Based on the hypothesis, the following research questions are formulated.

1. Is there a predominant learning style, as defined by the Gregorc Styles Delineator, of students who enroll in graduate online instruction?

2. Do students who enroll in online courses prefer specific online instructional methods?

3. Is there a relationship between learning styles and preferred methods of online instruction?

Need for the Study

Colleges and universities are currently offering courses and complete degrees online (wmw.setonworldwide.net; www. sin.suny.edu). The types of learning activities incorporated into the coursework are chosen by the instructor and may reflect the instructor's preferences rather than those learning experiences better suited to promote learning online. If a relationship does exist between learning styles and the students' preferred method of online instruction, the impact on course design, which determines the specific online activities, is significant. If a predominant learning style emerges from this study, the initial design of any online course can be modified to 
accommodate that style, or, can be modified to challenge the student to extend beyond that which is comfortable and natural, and explore different learning experiences. Additionally, since each learning community is different, the data may be used to adjust and refine teaching methodologies while a course is in progress. Activities, such as web-research, interactive assignments, and enhanced chat-room discussions can be added or minimized to address learning needs. In the same way instructors adapt and change teaching strategies based on student population in the traditional setting, so too must online professors be able to adapt and meet the needs of the students who learn online.

Course design is not the only area where the results of the study might have an impact. Another dimension is in the appropriate advisement of students. Students may be advised not to enroll in online education if their learning style is better suited for traditional methods of instruction. While attrition data is being collected, it is sometimes difficult to track. SWW reports that attrition for the Master in Health Care Administration program in 2001 through 2002 was approximately $23 \%$ (SetonWorldWide, 2003). While no specific reasons were given to explain the attrition rate, it has been suggested that learning style intervention can improve retention and student achievement (Nelson 
et al. 1993). Therefore, if the students' learning styles can be accommodated into the teaching methodologies employed in the online environment, a decreased attrition in online courses may occur. 


\section{Chapter II}

\section{REVIEW OF RELATED LITERATURE}

\section{Learning Styles Inventories}

Learning Styles Inventories (LSI) and their role in education have had a constant presence in the literature for well over sixty years. In the 1940 's, an individual's learning style was related to teaching methods and memory, but eventually expanded to include mental qualities (Seidel \& England, 1997).

The foundation of learning style assessment is in Jungian philosophy. Jung identified two basic psychological types: introverted and extraverted. An individual's psychological type affects his attitudes toward the object, or the world (Jung, 1923; Campbell, 1971). The extraverted preference deals with external signals while the introverted dimension deals with an internal process (Bokoros, Goldstein, \& Sweeney, 1992). Within the context of the psychological types, Jung presented four psychological functions of the psyche: thinking, feeling. sensing, and intuiting. These four orthogonal bipolar dimensions also affect how an individual perceives the world (Harasym et. al., 1995b). This link between the Jungian personality dimensions and how an individual perceives the world has been used as the fundamental basis 
for the Myers-Briggs Personality Type Indicator (MBTI) (Myers \& McCaulley, 1985), and several of the learning style inventory tools developed. Most notably are, the Kolb Learning Styles Inventory (Kolb, 1976), Canfield Learning Styles Inventory (Canfield, 1974), the GrashaReichmann Learning Styles Scales (Grasha, 1996), and the Gregorc Learning Styles Delineator (GSD) (Gregorc, 1982).

The MBTI, which measures personality rather than learning style, extends the Jungian dimensions into four bipolar scales that define personality traits: introvert vs. extravert, sensing vs. intuition, thinking vs. feeling, and judging vs. perceiving (Myers \& McCaulley, 1985). As a result, 16 different psychological profiles can be generated. It assesses how a personality type thinks, questions and prefers information dissemination. Harasym et al. (1995b) studied 259 nursing students and compared the scores achieved on the MBTI with their academic achievement, as demonstrated by four lecture and two laboratory examinations, in a first-year anatomy and physiology class. The analysis of variance indicated that there was no relationship between the personality types as identified by the MBTI and scores on anatomy and physiology examinations $(p=0.05)$. In the same study, the researchers also identified that one of the personality scales, judging vs. perceiving, merged with one another scale, sensing vs. intuition. The merger of 
these scales indicates that a potential problem may exist using this tool in future studies as it may fail to discriminate all of the scales and therefore limiting the interpretation of data.

The Kolb Learning Styles Inventory (Kolb, 1976), which also is based on Jungian philosophy, combines the dimensions of concrete experience and abstract conceptualization with active experimentation and reflective observation. This twelve-item selfassessment scale defines four learning styles representing two bipolar dimensions: concrete experience (CE), abstract conceptualization $(A C)$, reflective observation (RO) and active experimentation (AE). These are expressed in the individual's preferences for learning. While commonly used in research regarding learning styles, Koob and Funk (2002) reported that the reliability and validity of this instrument is "plagued with a number of conceptual and methodological problems" (p. 300). In a critical analysis of the instrument, Ruble and Stout (1994) examined the $1976 \mathrm{Kolb}$ LSI as well as the revised $1985 \mathrm{LSI}$. They argued that Kolb's utilization of low test-retest scores and Spearman-Brown half coefficients yielded the highest correlation between items, which, in contrast, Kolb reported as an average coefficient of .65 for the four styles. Ruble and Stout (1994) stated that these calculations inflated the correlation coefficients, as Kolb did not use random samples. In their 
conclusions, they asserted that the tool should not be used to determine learning styles. Cornwell, Manfredo, and Dunlap (1995) tested 277 Tulane University students as well as 40 corporate professionals with the Kolb LSI 1985 instrument. Using a factor analysis, the findings supported the bipolar dimensions of "feeling" and "watching", but "thinking" and "doing" emerged as two separate dimensions. Therefore, they found poor support for the bipolar dimensions as described by Kolb and cautioned researchers about its use in interpreting learning styles. Koob and Funk (2002) also concluded that in spite of its popularity, the Kolb LSI misrepresents large groups of people and is most likely inaccurate. The authors urged all researchers to evaluate the validity and reliability of not only the Kolb LSI, but also all LSIs prior to their use.

The Canfield Learning Styles Inventory is another commonly used tool, but it does not incorporate the Jungian link with personality. It uses a twenty-one point scale to assess four different dimensions: conditions for learning, area of interest, mode of learning, and course grade expectation (Canfield \& Lafferty, 1974). Only the first three dimensions are used to create a "learning typology" that describes the learning style. The fourth domain (course grade expectation) is self-contained and not incorporated into the "learning typology." Eide, Geiger, and 
Schwartz (2001) used this tool in their assessment of learning style in accounting students. The researchers' evaluation of the tool used testretest methodology, administering two versions of the instrument, one standard and the other scrambled, to 521 accounting students. Statistical analysis utilized alpha coefficients as a measure of test-retest reliability, and Kappa coefficients to determine the stability of the learner types. The alpha coefficients between the pretest group (0.67) and post-test group (0.77) represented a moderate correlation between groups. The Kappa coefficients, which measured stability of the learning types, were 0.298 and $0.346(p<.0001)$. These small numbers represent an inability to classify students consistently. The researchers concluded that there were "moderate internal consistency reliability and considerable classification instability" (p. 341) and little statistical support for the learner typology as defined by Canfield. Because of the dimensions of learning conditions (which includes the type of course materials used), subject preference, and mode of learning, the Canfield LSI therefore tends to measure instructional preference and not a true "learning style" (Olson \& Scanlan, 2002).

The Grasha-Reichmann Learning Styles Scale is a 60 item self evaluation inventory that utilizes a five point Likert scale and represents six learning styles (Grasha, 1996). The six styles are competitive (students 
who learn to out-perform others in the class), collaborative (students who share ideas with others), avoidant (students who are not enthusiastic about attending class), participant (the "good citizens" of the class), dependent (students who show little intellectual curiosity), and independent (confident in learning abilities)(Logan \& Thomas, 2002). Scoring results in a percentile ranking of the six styles and are categorized as low, moderate or high. The questions used to determine the six learning style categories ask students to rank interactions with instructors and peers, as well as questions related to the learning environment. Therefore, the six styles represented by the GrashaReichmann tool are more indicative of one's social and behavioral preference (Brown, 1998) rather than a true learning style as defined in the bipolar Jungian construct.

Anthony Gregorc constructed a model based on a twodimensional level between perception and ordering. The bipolar dimensions for perception ranges from abstractness to concreteness while the continuum for ordering ranged from random to sequential (Gregorc, 1982). The Gregorc Learning Style Delineator requires the subject to complete a matrix consisting of ten sets of four words. The subject is asked to rank the words within a set with a score of four as being most descriptive and a score of 1 as least descriptive of him or 
herself at the point in time the tool is administered. The subject is instructed to rank the words based on the first reaction to the words. The scores from the word groupings are then totaled and mapped according to the scoring matrix developed by Gregorc to arrive at four learning styles, each with its own characteristics. These characteristics are summarized in Table 1. 
Table 1

Summany of Gregorc Learning Styles and Personality Characteristics*

\begin{tabular}{ll}
\hline Learning Style & Characteristics \\
\hline Concrete-Sequential (CS) & Structured, practical, predictable, \\
& thorough
\end{tabular}

Abstract-Sequential (AS) Logical, analytical, conceptual, studious

Abstract-Random (AR) Sensitive, sociable, imaginative, expressive

Concrete-Random (CR) Intuitive, original, investigative, able to resolve problems

From "Learning is a Matter of Style" by A.F. Gregorc and K. Butler, 1984, Vocational Education, 59, p. 27 - 29; and "Validation of the Gregorc Learning Style Model" by M. Thompson, 1989, Occupational Education Forum, 50, p. 28. 
Various researchers have tested the validity and reliability of the GSD. Gregorc (1982) reported alpha coefficients ranging from .89 to .92 for assessments done six hours to eight weeks apart, respectfully. O'Brien (1990) administered the GSD to 263 undergraduate students within the course of one academic semester and reported lower values for the alpha coefficients ( .51 to .64). Joniak and Isaksen (1988) studied two groups of undergraduates $(\mathrm{N}=109$ and $\mathrm{N}=135)$ in an attempt to correlate the GSD with Kirton's bipolar dimensions of adaptor-innovator and measure internal consistency of the GSD, which yielded reliability coefficients of .23 to .66 for all four dimensions. While these values reported by Joniak and Isaksen are significantly lower than those reported by Gregorc (1982) and O'Brien (1990), the researchers suggest that the difference may represent test fatigue of the subjects.

In an attempt to further validate the use of the GSD. Thompson (1989) studied six instructors. Thompson found that those instructors who scored as concrete learners utilized concrete instructional methods in their classrooms. In addition, it was found that teachers' classroom behaviors were associated with their learning styles. O'Brien (1990) used the factor methodology, LISREL 7, as a confirmatory factor analysis in order to determine construct validity of the Gregorc tool. LISREL 7 was chosen for its ability to accurately construct matrices using ordinal data 
(Jöreskog \& Sörbom, 1989). O'Brien found that the individual measures of the estimated error variance for the individual learning style were insufficient, but jointly the four cognitive styles provided for an adequate measurement of style.

Even with its limitations, Seidel and England (1997) conclude that, "the reliability of the Gregorc learning styles delineator is sufficient to investigate the construct validity in terms of its use in the classroom" (p. 10-11). Additionally, Ruble and Stout (1994) argue that the ipsative scoring method of all LSIs can be the source of statistical weaknesses in their measurement ability.

While the strengths and weaknesses of all commonly used LSIs have been presented in this report, the strength of the GSD outweighs the weakness and the literature supports the use of the GSD in learning styles research. The literature indicates that the GSD appears to be the positive choice by support or default in terms of its construct validity and reliability as well as extending the Jungian concept of bimodal or bipolar dimensions. 


\section{Application of LSIs in Traditional Education}

The application of LSIs in all aspects of education is well represented in the literature, warranting use in both traditional and online educational settings (Delahoussaye, 2002). In research attempting to link perceptual learning styles to performance, sex, age. and academic standing in student enrolled in remedial courses, Ginter, Brown, Scalise, and Ripley, (1989) asked students to rank the four most effective methods of learning that were the most effective. While the number of respondents for each group varied, the researchers found that those students who preferred interactive learning had a higher GPA $(\underline{M}=2.60, n=28)$. In addition, they found that learning styles differed with age $(\mathrm{F}=2.42, \mathrm{p}<.05)$.

Multiple studies have explored learning styles and various relationships in students enrolled in health professions education. A four-year longitudinal study of $\mathbf{4 8}$ dental students was conducted by Hendricson, Berlocher, and Herbert (1987) using the Gregorc Style Delineator. While no change in learning style was statistically significant over the course of the study, there was a yearly increase in the number of concrete/sequential learners $(n=44$ in freshman year, $n=50$ in senior year). In spite of the low sample size, this study is significant as it attempted to track learning styles longitudinally. While the small 
differences observed in the increased number of concrete/sequential learners, it may be attributed to the nature of dental education, or it may also be an indication of students ability to change or stretch their learning styles to meet the various types of instructional methods used. In support of this notion, several researchers (Briggs, 1978; Entwistle, Hanley, \& Ratcliffe, 1979) have suggested the presence of "strategic" learners in a class community. These are learners who are flexible and can adapt their learning style to changes in pedagogy.

Katz and Heimann (1991) compared the learning styles of students enrolled in five different health professional programs and practitioners $(N=629)$ to explore if any differences existed based on professional practices. They found that at the practitioner level, four of the five professions, occupational therapy, nursing, social work, and physical therapy, had the same learning styles preference for the concrete while first-year students displayed a difference in learning preferences from their professional counterparts. Only in the clinical psychology group were the learning styles similar in both practitioners and students. The implications of this study are significant in that learning styles in certain practitioners may change and evolve during the educational process. Furthermore, certain professions, such as 
clinical psychology, may attract individuals with strong preferences for a particular learning style, which will not change over time.

Success in a baccalaureate nursing students was examined using the Kolb LSI by Haislett, Hughes, Atkinson, and Williams. (1993). The Kolb instrument was given to 100 undergraduate nursing students, $95 \%$ of whom were female, the learning style was compared to their first semester grade-point ratio (GPR). They found that the most successful students, as defined as having the highest GPR, were the assimilators (쓰 $=2.70)$ and divergers $(\underline{M}=2.59)$ while accommodators had the lowest GPR $(\underline{M}=2.03$ ). Although the divergers comprised $19 \%$ of the sample, the results indicate that the accommodator group may be at greater risk for academic failure. Therefore knowledge of a student's learning style may lead to appropriate academic intervention by the instructor.

Harasym et. al. (1995a) used the GSD to examine the achievement of 260 undergraduate nursing students enrolled in anatomy and physiology using lecture and laboratory examination scores. Using mean value scores for each of the learning styles, the concrete/sequential learners had the highest test scores ( $M=27.265)$ while the concrete/random had the lowest $(M=22.572)$. Factor analysis yielded two constructs based on learning style and examination. No correlation between examination scores and learning 
styles was found. However, one criticism of the GSD did emerge. One of the bipolar scales (abstract vs. concrete) collapsed into the sequential/random scale. While this might preclude the GSD from use in future studies, the collapse may be a function of the way in which scores are ranked and may be an inherent problem in all LSIs (Ruble \& Stout, 1994).

Similarly, Harasym et al (1995b) used same methodology to explore achievernent of undergraduate nursing students in anatomy and physiology $(\mathrm{N}=259)$. In this study the Myers - Briggs Type Indicator (MBTI) was used instead of the Gregorc instrument. No meaningful relationship was found between the personality traits defined by the MBTI and examination scores. However, a similar collapse of two scales into a single bipolar scale of sensing/judging vs. intuition/perceiving occurred thus resulting in the inability to correctly interpret the data. Linares (1999) used a version of the Kolb LSI, as modified by Marshall and Merritt, to determine if a single, dominant learning style would emerge from a sample of students $(n=436)$ and faculty $(n=22)$ in baccalaureate nursing program, occupational therapy, physical therapy, physician assistant, and medical technology, or if learning styles are indicative of academic success. While $60 \%$ of the subjects $(N=458)$ were convergers, differences existed between the professions. 
Those in the occupational therapy program were equally categorized as convergers (37.5\%) and accommodators (37.5\%) while none from the medical technology group was an accommodator or diverger. In addition, there were no divergers in the physician assistant group. These results are contrary to those found by Katz and Heimannn (1991). Of note, however, differences were noted between the learning styles and race. African-Americans $(n=38)$ were predominantly convergers $(81.6 \%)$, with none categorized as accommodator or diverger. Hispanics ( $n-40$ ) were also predominantly convergers $(57.5 \%)$, while Asian students ( $n=22$ ) and Caucasians were distributed across all learning styles. This contrast, in spite of the low number of subjects, indicates that there may be a cultural influence on the way students of different ethnic backgrounds learn. Lastly, no relationship was found between learning style and academic success as defined by grade point average.

and Scanlan (2002) examined the relationship between learning styles and preferences for various instructional activities and teaching methods of graduate physical therapy students. The GSD and a preference survey were administered to 190 subjects. Of note was the emergence of the dual learning style $(n=65,34.2 \%$ ) as the dominant learning style. However, computer aided instruction ranked low as a 
preferred instructional method. Only weak correlations were found between learning styles and instructional preferences. The researcher suggested that the lack of any strong correlations may be due to a weakness of the GSD, or the ability of the students demonstrating the dual learning style to accommodate or adapt to a variety of teaching methods.

The literature presented reflects many studies that have explored learning styles and their relationships to gender, race, profession, and academic achievement (Ginter et al., 1989; Haislett et al., 1993; Harasym et al., 1995 (a); Harasym et al., 1995 (b). Hendrickson et al., 1987; Katz \& Heimann, 1991; Linares, 1999; Olson \& Scanlan, 2002). However, fewer studies have examined learning styles and online education.

\section{Application of LSls in Online Education}

Diaz and Cartnal (1999) were one of the first to compare the learning styles of online learners with on-campus students. They studied 40 online students and 63 on-campus students. Each group was enrolled in a health education classes that utilized the same textbook, syllabus and lecture content. Only the mode of delivery varied across the groups. The online students reviewed lecture material converted 
from Power Point to HTML, communicated through listservs and e-mail, and completed independent internet-based assignments. On-campus students received the material in the traditional lecture format. The Grasha-Reichmann Student Learning Styles Scale was used to assess each group's learning styles. This scale rates learners in a broad social interaction context by having the respondent rank interactions between peers and instructor as well as the learning environment. Utilizing a two-tailed $f$-test, the researchers determined that the difference in LS scores between the groups was not due to chance $(p<$ .05 , and $p<.011$. Correlation relationships found that the online learners were more independent and less collaborative than their in-class counterparts $(r=-.36, p<0.1)$. A positive correlation between collaboration and the competitive and participant styles was found in the on-campus group $(r=.51, r=.52, p<.01)$. These results indicate that the on-campus group was composed of the "good citizens," as defined by the Grasha-Reichmann instrument, who wanted to exceed the requirements of the syllabus.

To further determine if a difference exists between online learning and traditional classroom learning, Mehlenbacher, Miller, Covington, and Larsen (2000) compared an on-campus writing class to an online version of the same writing class. The sample was composed of 41 
students enrolled in an online technical writing course and 21 students enrolled in the same course offered, but using an on-campus model. The same instructor taught both the online and on-campus courses. Performance measures and outcome measures included student perception of writing competency, portfolio assessment, and final course grade. The Inventory of Learning Styles self-developed by Felder, and based on the Kolb tool, was used to determine the students' learning styles. The researchers found no significant difference in student outcomes $(t=-0.18, p<0.05)$ between the online group and the on-campus group, but did find that reflective learners fared better in the online version than sequential learners. In addition, females performed better in the web course than males $(t=3.70, p<.05)$ while no gender difference was observed in the traditionally taught course. In spite of the small sample size from the two course sections, and the unequal data set the course materials and instructor remained the same. Therefore, the differences observed in learning styles and better performance by female in the online course, may be attributed to the nature of online learning.

The Kolb LSI and a self-created survey were used by Karrupan (2001) to evaluate student access to an online lecture in two sections of an introductory principles of management course. The same instructor 
taught both sections. Web-materials supplemented, but did not replace, traditional teaching media in one of the sections. Studying 92 students, the Karrupan determined that the abstract learners (assimilators) accessed the web material more frequently (10.59 times) than the accommodators (4.85times) who preferred "hands on". However, no difference in test scores was observed $(\beta=0.53, p<.05)$. The results of this study are limited as no other pedagogical strategies were evaluated. However, of importance is the fact that multiple web access was preferred by one learning style, even though final course grades were not affected. Therefore, the research of Miller,Covington, and Larsen (2000) and Karrupan (2001) combined support that the learning styles of students' enrolled in online education play an important role in the academic achievement and method by which students with a particular learning style access information.

Recently, Andrusyszyn (2001) developed a questionnaire utilizing twelve learning preferences, which were placed on a bipolar scale, and six preferred styles of learning based on common learning style categories (hearing, reading, discussing, observing, doing and reflecting). The researcher did not use a standardized learning style assessment tool but piloted a questionnaire that was developed by a consensus group of four students and online faculty, thus achieving 
construct validity. This pilot questionnaire was subsequently given to a convenience sample of 25 students. The original questionnaire was revised based on feedback from the pilot study. No additional validity or reliability testing was performed on the questionnaire, therefore placing the collected data in question. However, the results of the study are significant as they represent the first attempt at analyzing learning styles assessment and instructional methods in the online environment. The revised questionnaire was then administered to 125 nurse practitioner students. Pearson-product moment correlation coefficients and repeated measures (ANOVA) found that no one instructional method dominated $(p<0.05)$. Andrusyszyn concluded that students preferred to learn in a variety of ways. Some students simply took distance learning as a matter of convenience rather than for the teaching method. Some of the results may be explained because of the demographics of the subjects. The subjects were predominantly female (96.3\%), and ranged between 31 and 50 years of age. The vast majority $(96.5 \%)$ reported conflicts with schedule, work and family commitments and other outside responsibilities. The subjects also admitted to being least familiar with "high-tech", but still chose the online approach anyway. Another difficulty with the interpretation of the results is that self-motivation to have professional success at the 
graduate nurse practitioner level, and the presence of strategic learners, could transcend learning styles.

Valenta, Therriault, Dieter, and Mrtek (2001) surveyed a sample of 74 undergraduate students enrolled in a general psychology class and graduate students enrolled in health informatics program at the University of Chicago. All were enrolled in their first web course. The average ages were 19 years for the undergraduates and 36 years for the graduate students and the gender distribution for the entire sample was 30 males and 44 females. The authors used a Q-methodology in which a survey consisting of 23 statements, developed by the researchers, concerning lifestyle, work place, and learning preference was administered during the first week of the web courses. Factor analysis yielded three factors: time and structure in learning (which included time management, self-paced learning, and ability to work at home) social interaction in learning (which included less participant discussion and fewer teaching subtleties), and convenience in learning (which included saving of travel time and saving of commuting costs). Students were asked to rank the relative importance of issues related to these three factors. The students gave to each statement rankings that ranged from +3 to -3 . Scores were tabulated for each factor. Scores from Factor 1, time and structure indicated that students preferred 
flexible time management and convenience. Factor 2 scores, social and interaction, revealed a concern for decreased discussion and loss of teaching subtlety. Factor 3 , convenience in learning achieved high scores for the ability to work at home and elimination of travel time. Although no formal learning style tool was administered to the subjects, the data achieved by the $Q$ methodology does give some insight into the learning typology. The information gathered from this analysis was subsequently used to enhance the design of online courses offered at this institution such that convenience was emphasized and opportunities for discussion were increased.

While learning styles have been used infrequently in the assessment of students enrolled in online education, another significant dimension has emerged. In the last study cited, it was noted that online course design and the types of interactions experienced by students are important for learning. Therefore, it is necessary to explore the literature that addresses the issues of online course design, and the ability of online faculty to design meaningful and purposeful online instructional methods. 


\section{Online Course Design and Faculty Development}

Course design is a critical component of an online course and is linked to educational objectives. For example, Liow and Betts (1993) surveyed students from three disciplines and compared their ranking of educational objectives to that of the faculty. The authors demonstrated that students ranked "skill development" and "understonding concepts" as major course objectives and that lecture was the least favored delivery method. The authors argued that this study should encourage faculty to acquire more active-learning pedagogy when designing or revising a course. Traditional lectures are not emphasized in an online course while interactive methodologies are emphasized. Therefore, the nature of online learning and its diverse instructional methods may have a strong appeal to learners.

The importance of course design, especially in the online learning environment, has resulted in a significant body of literature. While transitioning an on-campus Leadership in Organizations course to the online environment, Hutton (1999) found, based on a student survey ( $N$ $=66$ ), that structured learning goals and threaded discussions were necessary for online learning. From that initial group of web course participants, she also learned from course evaluations that the students should be allowed to practice and improve course platform navigation 
skills. This is also corroborated by SLN, which incorporates a course orientation and "icebreaker" module for all SLN courses (SLN, 2000). This module allows students to practice the submission of written assignments and discussions as well as navigating all other features of the course platform.

Swan et al. (2000) surveyed students enrolled in SLN courses in the spring of $1999(\mathrm{~N}=1,406)$. One way analysis of variance showed that students had a higher level of satisfaction and learning as demonstrated by courses that had higher instructor interaction $\left(F_{\{3,1402\}}=\right.$ 188.97, $\mathrm{p}<.01$, and $\left.\mathrm{F}_{(3,1402\}}=168.25, \mathrm{p}<.01\right)$ interactions with classmates $\left(F_{\{3,1402\}}=68.91 .27, p<.01\right.$ and $\left.F_{\{3,1402\}}=50.27, p<.01\right\}$, and higher levels of activity $\left(F_{(3,1402)}=44.21 . p<.01\right.$ and $\left.F_{(3,1402)}=90.20, p<.01\right)$. Therefore, courses designed to include a significant amount of instructor and student interaction, and courses that provide an active pedagogy may result in greater student satisfaction and increased learning.

It cannot be assumed that faculty intuitively know how to design an online course and are prepared to manage an online course. The process of teacher education includes issues of curriculum and course design. Online course development should not be excluded from this process given the importance of course design and its impact on student learning. 
Therefore, faculty development is also a key factor in online course development. Both SLN and SWW provide technical training and resources for online faculty. Andrews, DiGangi. Winograd, Jannasch-Pennell, and Yu (1999) outlined a multidisciplinary approach, incorporating academia and instructional support services, to web course design. Critical to the course design was the inclusion of faculty in the design aspect beyond their role as the "master" of the subject matter. Time, navigation issues and accessibility for all students, including the disabled were also key components in the course design. While not supported by statistics, this article outlined the importance of a multidisciplinary approach to web-course design.

Jiang and Ting (1998) evaluated students' perceived learning in an online course using spring 1997 SLN data. They surveyed 183 SLN students and asked if the grade-weight assigned to interactive participation, as well as the degree of course participation, gave them a perceived sense of learning. Correlation analysis found that the more interactive the course design, the more the students' perceived learning (grade-weight of the discussion, $r=.56, p<.01$; amount of discussion by the students, $r=.62, p<.01$ ). Data analysis also revealed that the more interactive the professor, the more the students participated $(r=.61, p<.01)$. These findings support those found by 
Swan et al. (2000). However, class size and the number of responses per student had no correlation with perceived learning $(r=.04, p<.05)$. Using a case study methodology, Bullen (1998) examined the quantity and quality of student responses $(N=13)$ in a computer conferencing course and the effect on critical thinking. Using structured interviews of students and instructor, the author gathered data regarding perceptions of learning and of the use of critical thinking. Additionally, the number of student responses posted in the course, as well as the instructor's rating of the student's responses (which determined the degree of critical thinking), were used as the benchmarks. In spite of the small number of subjects ( $N=13)$, the results indicated that the more interactive the course design, the more the students participated and exercised critical thinking. In two studies, Swan (2001) \& Swan et al. (2000) also found course design and instructor interaction as those factors that most influenced student satisfaction and perceived learning. In the 2000 study, Swan et al. analyzed survey responses from 1,406 students enrolled in online courses offered by $S L N$ in 1999 to determine the perceived level of course satisfaction. The survey also included questions regarding course design features such as use of a textbook, number of modules, consistency of design between modules, voice used by the instructor, 
and number and type of student -instructor interactions. The results showed that the more interactive the instructor, the higher student satisfaction $(r=.761, p<.01)$. Students also felt that more learning occurred $(r=.437, p<.010)$ if instructor interaction was high.

Bi (2000) interviewed faculty $(N=10)$, instructional designers $(N=$ 7) and students ( $N=24$ ) at several universities located in different geographical regions of the United States regarding web course design. The study found four essential factors in web course design that all faculty should consider. First, the design of the course should be specific for the nature and abilities of online learners. Second, the design should consider immediate and long-term goals and objectives. Third, the design should be systematic. The fourth point, which is the most critical, is that the design should meet the instructional needs of the faculty and delivery of the subject matter, and should not be a showcase for the latest technology.

The literature presented supports the theme that course design has a significant impact on student participation in learning. It has also been demonstrated that the degree of instructor interaction is another benchmark for learning in the online environment (Karrupan, 2001; Swan, 2001, Swan et al, 2000). Can course design be manipulated to meet the needs and learning styles of the students? To date, only a few 
studies have demonstrated that learning activities could be designed to meet the pedagogical needs of the students based on their learning styles and achieve positive outcomes.

\section{Course Design and Learning Styles}

In an attempt to gather information about motivation and selfdirected learning, Tsay, Morgan, and Quick (2000) surveyed 449 current web-students and 140 inactive web-students at the first online university in Taiwan. Students were asked to assess motivation and self-directed learning readiness. In addition, the 63 questions of the survey were factored into the following categories: facilitation of self-directed learning, institutional support services, orientation programs, instructional style, course design adaptations and interpersonal interactions. The data analysis revealed significant differences in six of the seven factors (adjusted $\dagger$ test, with $p$ values ranging from $p<.05$ to $p<.01$ ). Although not directly related to students' learning styles, facilitation of selfdirected learning is an essential factor in course design to assist students to meet their personal needs through the use of various experiences.

Student satisfaction, degree of learning and degree of selfdirection can all be attributed to the inherent design of the online course (Swan et al., 2000). In addition, research supporting the 
assessment of learning styles, the correlation between learning styles and instructional preference, has been presented. The exploration of an important question remains: is there support in the literature that justifies the assessment of students' learning styles in order to guide course design and course revision?

Simon (2000) used the Kolb Learning Style Inventory (LSI) to determine whether the learning style assessment and training method of $\mathbf{4 5 0}$ United States Navy personnel had an impact on end-use computer satisfaction. All subjects were evaluated to be "novice" computer users. The subjects were given the Kolb LSI and then trained in the use of the Micro-SNAP II computer system. The training method was divided into three teaching conditions: instruction, exploration, and behavior modification. Likert scale surveys were developed to assess comprehension, skill, and satisfaction at three intervals. Simon found significant differences in the preferred training methods based on the Kolb learning style. Specifically, differences were reported between the reflective/observers and their active/experimentation counterparts for skill acquisition $(Z=9.74, p=.04)$, and comprehension $(Z=8.67, p=.04)$. There were no differences reported in end-user computing satisfaction based on the feaching interventions. Therefore, those trainees whose learning styles were matched with training method were more 
successful. This supports the notion that course design can be manipulated in order to accommodate the learning styles of the students.

Seidel and England (1997) investigated learning styles and instructional preferences in 100 liberal arts students who completed the Gregorc Style Delineator (GSD) and a self-designed questionnaire about instructional and assessment preferences. They found that $59 \%$ of the students displayed a dual learning style with the concrete/sequential learning style as the dominant single style (15\%). The data analysis showed that those students who scored as concrete/sequential learners preferred structured lectures and independent laboratory work $(p=.003)$ as well as testing technique (such as essay, multiple choice, short-answer tests) $(p=.001)$. Therefore, the data analysis indicates that the GSD does discriminate between learning style and assessment preferences in liberal arts students and that innovative teaching methods should be encouraged to accommodate these learning styles or to mismatch them in order to challenge students to expand beyond their comfort level. Therefore, the ability to discriminate between preferences in learning and assessment, as described by Seidel and England (1997), was a factor in the decision to use the GSD in this current study. 
Ross and Schulz (1999) used the GSD to investigate humancomputer interaction. Specifically, they investigated whether varying teaching methods should be encouraged to accommodate cognitive styles. Seventy University of Calgary undergraduates enrolled in various majors were given the Gregorc Learning Styles Delineator. The other measure was the degree of learning in a computer assisted instructed (CAl) single-rescuer cardiopulmonary resuscitation (CPR) class. Using a pre-test post-test methodology, which was comprised of twenty multiple choice questions and use of the CAl materials, the researchers found that patterns of learning (such as screen navigation and time spent on various parts of the CAl) were not significant among the dominant learning styles of concrete/sequential $(n=20)$ and concrete/random $(n=20)$ at $p<0.05$. However, the manner in which students learned did play a significant role in learning outcomes. The abstract-random group had a drop in the post-test scores of $10 \%$, while all other groups demonstrated a gain in post-test scores (scores increased between $10 \%$ to $18 \%$ for the other learning styles). Ross and Schulz concluded that computer aided instruction may not be appropriate for all students and may be attributed to a mismatch between learning style and teaching method. Therefore, knowledge of the students' learning styles can aid an instructor in developing flexible 
teaching methods as well as helping students to "stretch", or vary from their preferred learning style if they are confronted with an uncomfortable or unfamiliar learning environment (Gregorc, 1984). Gregorc (1984) and Thompson (1989) investigated the relationship between learning styles and instructional methods. In a study of 100 subjects, Gregorc found that individuals had strong preferences for instructional methods that correlated with their learning disposition. In the validation of the Gregorc learning style model Thompson (1989), over a two-day period, observed the teaching methodologies used by six teachers in a professional training program. The results of their studies have determined which cognitive learning style, as defined by Gregorc, corresponds to particular media, teaching methods and practices. These are given in Table 2. 
Table 2

Media, Teaching Methods and Practices*

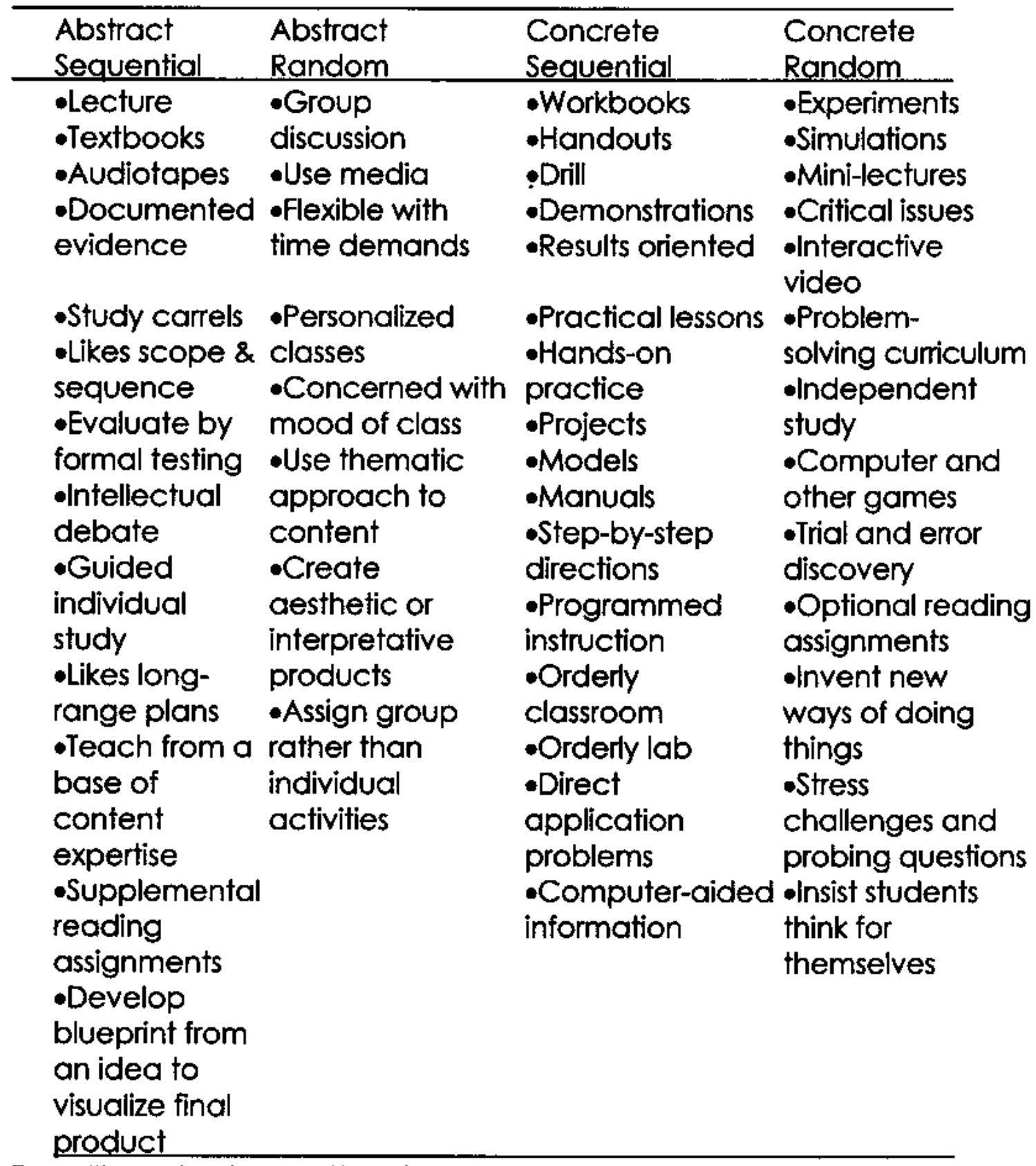

From "Learning is a Matter of Style" by A.F. Gregorc and K. Butler, 1984,

Vocational Education, 59, p. 27 - 29; and "Validation of the Gregorc 
Learning Style Model" by M. Thompson, 1989, Occupational Education Forum, 50, p. 28. 
Based upon the literature reviewed, the rationale for the application of learning style assessment and adaptation of pedagogy to meet the needs of, or to challenge, the learning styles of course participants is valid. This rationale can also be extended to the pedagogy offered in the online environment. The nature of online instruction, course design and online instructional methods should be coupled with learning styles assessment to determine if relationships exist between these variables.

Since the number of online course offerings at colleges and universities and the number of students in these courses will continue to grow, the need to investigate the relationships between learning styles and online learning is imperative. This may include research exploring possible relationships between learning styles and preferred methods of instruction, assessment methods, and student demographics. Findings regarding these relationships will substantiate the need to enhance the nature of online learning. These can be used to increase student satisfaction and course participation, as well as to challenge faculty to design online courses using the instructional methods that are most suitable for the audience. 
Chapter III

METHODS

Research Design

The research design for this study was a descriptive correlation study utilizing a two-part survey.

Subjects and Procedures

The subjects consisted of a convenience sample of all graduates students $(N=331)$ currently enrolled in an active online graduate course offered by SetonWorldWide as of May 15, 2003. These students were enrolled in the Master of Arts in Counseling, Master of Arts in Strategic Communication and Leadership, Master of Education and Supervision, Master of Health Care Administration, and Master of Science in Nursing. Permission was obtained from Philip DiSalvio, Ed. D., Director of SWW, granted permission (Appendix A) to solicit participation of this sample.

An expedited approval from the Seton Hall Institutional Review Board (IRB) (Appendix B) was obtained. A two-part survey consisting of Part A, the Gregorc Learning Styles Delineator and Part B, a questionnaire which asked the students to rate their preference of on- 
line instructional method, was administered. Permission to use the Gregorc Learning Style Delineator was obtained (Appendix C) from Anthony Gregorc, Ph. D.

Since the study involved online courses, all of the research documents, the Solicitation Letter (Appendix D), Informed Consent (Appendix E) and survey tool were converted into an electronic format by eCollege, a company retained by SHU, which administers the platform for delivery of all SWW courses. Their services include course development and support, program management and reporting, and help desk services (www.ecollege.com). When students logged-on to their SWW courses, they were asked by the Solicitation Letter to proceed with the voluntary completion of the survey. Students had the option of completing the survey with the initial prompt, completing the survey at another time during the survey period, or not completing the survey at all. When a student selected the prompt to complete the survey, it acted as the student's electronic signature for consent to participation. If a completed survey was submitted, the prompt to participate no longer appeared. Only those students who had not yet participated continued to receive the prompt after logging - on to the course for the two-week survey period. 
Authentication specifications were established by eCollege that prevented multiple submissions by the same student even if that student was enrolled in multiple courses, thus restricting each respondent to one submission. The log-on identifier was not used to associate any responses to a particular student thus assuring anonymity. All data collection occurred within the course management system for SWW. After the two-week survey period, data were collected and exported to diskette. All surveys were then removed from the courses by the assessment administrative team at eCollege.

\section{Instrumentation}

\section{Part A: The Gregorc Learning Styles Delineator}

The Gregorc Learning Styles Delineator (Appendix F) is a tenquestion word matrix of four word groupings. The participant rates which word within that grouping is most descriptive or least descriptive at that point in time using a four-point scale. The participant is instructed to react to the words and not ponder their meaning or grammatical sense of the word-grouping. The GSD was selected for use in this study over the Myers-Briggs Personality Type Indicator, the Kolb LSI, the Canfield instrument, and the Grashsa-Reichmann tool for several reasons. First, its ease of administration to online students would 
allow students to respond quickly. Additionally, the initial intent of the instructions was easily maintained. Second, it was easy to score with easily reportable scales. Lastly, the reliability and validity of the GSD was supported in the literature. As previously mentioned, Gregorc has reported high correlations between test-retest scores as shown in the literature review (Gregorc 1982). Although other the correlations achieved by other researchers were lower (Joniak \& Isaksen, 1988; O'Brien, 1990; Thompson, 1989), the GSD remains a valid and reliable tool. In addition, variable analysis has been performed between the GSD scores, and other variables. These included variables such as age, years of teaching experience, income, birth order, age-gap between siblings, and handedness. No relationship was found between the GSD and these variables at $p<0.05$ (Gregorc, 1982). Although no further studies were performed to support these findings, the results obtained from the GSD are not influenced by other extrinsic factors so that the interpretation of the results is, therefore, free of any confounding biases or influences. The only extrinsic influence on performance on the GSD may be attributed to over-achievement (Gregorc 1982). These may be individuals who go beyond their learning style in order to achieve academic success. In addition, the GSD has been used in several studies investigating learning styles and student preferences (Seidel \& 
England, 1997; Olson \& Scanlan, 2002) and computer-aided instruction (Ross \&. Schulz, 1999).

The strengths and weaknesses of other learning style instruments were presented previously in the literature review. Interestingly, it was noted that the MBTI is defined as a personality assessment tool used to aid teaching (Drummond \& Stoddard, 1992). Furthermore, the Kolb LSI had many issues of validity and reliability (Ruble \& Stout, 1994, Koob \& Funk, 2002) while the Canfield and Grasha-Reichmann tools do not measure learning styles, but learning and social preferences (Brown, 1998; Olson \& Scanlan, 2002). Therefore, the GSD was determined to be the most appropriate instrument to measure learning styles in this sample.

\section{Port B: Questionnaire}

In order to determine what types of online pedagogy were being incorporated into the graduate online courses offered by SWW, a pilot questionnaire was devised by the researcher (Appendix G) and distributed to SWW faculty $(N=12)$ at a Faculty Roundtable held on January 17, 2003. Table 3 is a summary of the responses to that questionnaire. This pilot study served to insure that no ambiguous or unfamiliar terminology regarding online instructional methods was used and to insure that these types of instructional methods would be familiar 
to the subjects. Based on the responses of the online faculty, the statements regarding the use of games and required on-campus examinations were eliminated from the initial questionnaire.

Part B of the survey (Appendix $H$ ) consisted of demographic questions concerning type of degree program in which the student was enrolled, age, gender, length of time enrolled in the degree program. number of web courses taken, reasons for enrolling in a web course, and satisfaction with the degree program, as well as ratings of online instructional methods. Students were asked to rate each instructional method using a Likert scale ranging from Least Beneficial (1) to Most Beneficial (5). 
Table 3

Instructional Activities Used by SWW Faculty $(\mathrm{N}=11)$

\begin{tabular}{|c|c|c|c|}
\hline instructional Activity & Always & Sometimes & Never \\
\hline Textbook required & 11 & 1 & 0 \\
\hline Assigned textbook readings & 11 & 1 & 0 \\
\hline Maintain an E-journal & 4 & 6 & 1 \\
\hline Readings from materials on E-reserve & 2 & 8 & 2 \\
\hline Multimedia resource centers & 1 & 6 & 4 \\
\hline Remote databases & 4 & 6 & 1 \\
\hline Mini-lectures used & 2 & 8 & 2 \\
\hline Chat rooms & 4 & 4 & 3 \\
\hline Threaded discussion & 12 & 0 & 0 \\
\hline Critical issues or current discussions & 10 & 2 & 0 \\
\hline Student-driven discussions & 8 & 4 & 0 \\
\hline E-mail & 6 & 5 & 0 \\
\hline Mandated number of postings per week & 6 & 4 & 1 \\
\hline Group assignments & 7 & 3 & 2 \\
\hline \multicolumn{4}{|l|}{ Group assignments posted } \\
\hline to the entire class & 2 & 7 & 3 \\
\hline \multicolumn{4}{|l|}{ Group assignments posted } \\
\hline to professor & 0 & 8 & 3 \\
\hline Individual assignments & 8 & 2 & 1 \\
\hline Postings to a Webliography & 5 & 7 & 0 \\
\hline \multicolumn{4}{|l|}{ Evaluations and critiques } \\
\hline of related web sites & 2 & 7 & 2 \\
\hline Self-assessment quizzes & 1 & 7 & 3 \\
\hline Online examinations & 1 & 6 & 4 \\
\hline On-campus examinations & 0 & 0 & 12 \\
\hline Games, puzzles, or crosswords & 0 & 2 & 9 \\
\hline Case studies & 4 & 7 & 1 \\
\hline Interactive videos & 0 & 6 & 5 \\
\hline Supplemental CD-ROM & 0 & 4 & 7 \\
\hline Links to online tutorials & 1 & 6 & 4 \\
\hline Active role of instructor & 12 & 0 & 0 \\
\hline Asynchronous activities & 5 & 5 & 1 \\
\hline Synchronous activities & 2 & 6 & 4 \\
\hline
\end{tabular}


Data Analysis

To encourage prompt student participation, the survey was available for a two-week period. After that period of time, all collected data were delivered to the researcher on a diskette by ecollege. Of the total of 331 students who had access to the survey, 189 students actually did access the survey, which is a response rate of $57.1 \%$. However, of the 189 students, 48 accessed the survey but exited without answering any of the survey questions. Of the remaining 141 surveys, 45 were either incomplete or incorrectly completed and were eliminated from the study. The summary of the survey responses is contained in Table 4. 
Table 4

Summary of Survey Responses ( $N=189)$

\begin{tabular}{lll}
\hline Survey Response & $\underline{\mathrm{n}}$ & $\%$ \\
\hline Completed surveys & 96 & $50.8 \%$ \\
Blank surveys & 48 & $25.4 \%$ \\
Incomplete surveys & 45 & $23.8 \%$ \\
\hline
\end{tabular}


The remoining 96 surveys, representing a final response rate of 29.0\%, were analyzed using SPSS statistical software, version 9.0 (SPSS, 1999). The learning styles of the respondents were determined by utilizing the scoring instructions provided in the GSD users manual (Gregorc, 1982). The word grouping scores were tabulated and placed on the scoring grid. A score of 27 or greater was used to determine each of the learning styles. Descriptive statistics including frequencies, means, percents, and standard deviations were computed. The mean scores and standard deviations for each of the learning styles types were calculated and compared to the same data obtained by Gregorc (Gregorc, 1982) to provide validation of the results of this study. Correlation data for the various learning types and the methods of online instruction were computed using the Pearson-product moment correlation coefficients. This statistical measure was chosen because it can be used for paired observations for the same set of individuals, and the size of the sample does not affect the size of the correlation coefficient. The scores were converted from an ordinal to an interval scale prior to analysis. Lastly, the Pearson-product moment correlation coefficient is the most commonly used correlation statistic in the behavioral science research (Hinkle ef al. 1998). A mean score was calculated for all dual learning styles in order to submit them to 
correlation analysis. The number of variables was then reduced into a smaller number of constructs using principal axis factoring analysis in order to investigate the possible relationships between learning styles and online instructional methods.

The methodology chosen for the principal components analysis was the Varimax-Kaiser orthogonal factor analysis, which incorporates rotation. This factor extraction methodology allows factors to load high on a small number of variables, which makes the resulting factors easier to interpret. Additional rotational analysis increases the ability to interpret the factors (Stevens, 1996). As suggested in Stevens (1996), only those factors with an eigenvalue greater than one were considered for inclusion in the factor analysis. Finally, the factors were examined using a scree graph. Only those factors that occurred before the curve leveled, and those that accounted for $50 \%$ of the variance were retained (Stevens 1996). Six factors emerged. Pearson-product moment correlation coefficients were calculated to determine if relationships exist between the factors and learning styles. In analyzing the correlation coefficients for any significance, $p$ values were set at a minimum of .05 .

The degree of correlation was determined according to Hinkle, Wiersma, and Jurs (1998). Correlations that range between .90 and 1.00 
represent a very strong correlation. Those that range between .70 and .90 are high, .50 and .70 are moderate, .30 and .50 weak, and those between .00 and .30 represent little, if any, correlation. 


\section{Chapter IV}

RESULTS

\section{Respondent Demographics}

The total number of surveys returned was 189, which is a response rate of $57.1 \%$. Due to incompleteness or errors, 93 surveys were eliminated. Of the 96 completed surveys, 69 of the respondents were female $(71.9 \%)$ and 26 were male $(27.1 \%)$. One respondent chose not to identify his or her gender. The mean age of the respondents was 38.08 years, with the youngest being 23 years old and the oldest 83 years old. The subjects represented a cross section of all the graduate degree programs offered by SWW. Students enrolled in the Master of Education and Supervision (EDAS) program constituted the largest group of respondents (26.0\%) while those enrolled in the Master of Arts in Strategic Communication and Leadership (MASCL) program were the smallest group (11\%). The complete distribution of the respondents is shown in Table 5. 
Table 5

Distribution of Respondents According to Degree Program ( $N=96$ )

\begin{tabular}{lll}
\hline Program & $\underline{\mathrm{n}}$ & $\%$ \\
\hline Master Education Administration/Supervision & 25 & $26.0 \%$ \\
Master of Arts, Counseling & 23 & $24.0 \%$ \\
Master Health Care Administration & 19 & $19.8 \%$ \\
Master of Science/Nursing & 18 & $18.8 \%$ \\
Master Arts/Strategic Communication/Leadership & 11 & $11.5 \%$ \\
\hline
\end{tabular}


In order to determine if the students were novice or experienced online learners, the respondents were asked to indicate the length of time enrolled in their programs and to indicate how many web courses had been taken previously. The vast majority of the students were enrolled in their degree programs longer than four months $(97.9 \%)$. Only $6.3 \%$ of the students indicated that this was the first web course taken while $83.3 \%$ had taken three or more web courses.

The Online Program

The subjects were also asked several questions regarding their rationale for enrolling in an online program as well as their level of satisfaction with their respective programs. Convenience was the most frequent reason ( $91.7 \%$ ) given for choosing online learning while $46.9 \%$ cited the appeal of online learning as a major reason for enrolling in an online graduate program. Table 6 lists the percentages per reason given by the subjects for selecting online learning. 
Table 6

Reasons for Enrolling in an Online Program

\begin{tabular}{lll}
\hline Reason & $\underline{n}$ & $\%$ \\
\hline Convenience & 88 & $91.7 \%$ \\
Appeal of online learning & 45 & $46.9 \%$ \\
Course content & 43 & $44.8 \%$ \\
Interactive pedagogy & 21 & $21.9 \%$ \\
Course not offered as a traditional course & 10 & $10.4 \%$ \\
\hline Note: Percentages do not add up to 100\% as respondents were asked \\
to choose as many responses as appropriate.
\end{tabular}


When asked about satisfaction, the majority of the respondents (72.9\%) indicted that they were completely satisfied with their program and $22 \%$ were somewhat satisfied, while only $5.2 \%$ of the respondents indicated any degree of dissatisfaction with their degree programs. The level of satisfaction with the online programs data is shown in Table 7. 
Table 7

Level of Satisfaction with Online Program

\begin{tabular}{lcc}
\hline Level of Satisfaction & $\underline{\mathrm{n}}$ & $\%$ \\
\hline Satisfied & 70 & $72.9 \%$ \\
Somewhat satisfied & 21 & $21.9 \%$ \\
Somewhat dissatisfied & 4 & $4.2 \%$ \\
Dissatisfied & 1 & $1 \%$ \\
\hline
\end{tabular}


Questions were asked to determine preferences for logging-on courses. Respondents could choose as many of the log-on times that were appropriate as the subjects could possibly log-on several times a day at varying times. Therefore, the percentages of the responses do not add to $100 \%$. The vast majority of the subjects preferred evening log-on times. These ranged from early evening (32.3\%), evening $(60.4 \%)$, to late evening (44.8\%). Surprisingly, $41.7 \%$ preferred an early morning log-on time. The summary of all preferred log-on times is found in Table 8. Ninety-five (99\%) of the subjects preferred the asynchronous environment to the synchronous environment. 
Table 8

Preferred Log-on Times

\begin{tabular}{lll}
\hline Log-on Time & n & $\%$ \\
\hline Evening & 58 & $60.4 \%$ \\
Late evening & 43 & $44.8 \%$ \\
Early morning & 40 & $41.7 \%$ \\
Early evening & 31 & $32.3 \%$ \\
Mid morning & 26 & $27.1 \%$ \\
Late afternoon & 23 & $24.0 \%$ \\
Early afternoon & 18 & $18.8 \%$ \\
Late morning & 15 & $15.6 \%$ \\
\hline
\end{tabular}

Note: Percentages do not add up to $100 \%$ as respondents were asked to choose as many responses as appropriate. 
The GSD

After scoring the GSD according to the Gregorc rubric (Gregorc, 1982), minimum and maximum scores, mean scores and standard deviations were calculated for all the learning style types and compared to the values reported by Gregorc. $(1982$, p. 36$)$ in order to validate the data obtained in this study. The mean scores calculated from the learning style scores obtained in this present study were for the

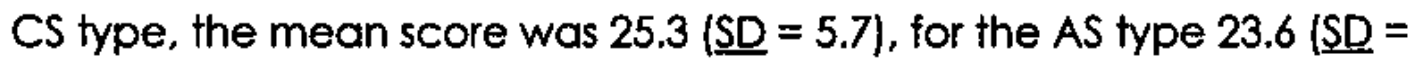
4.7), for the AR type $25.7(\underline{\mathrm{SD}}=5.2)$, and for the CR type $25.2(\underline{\mathrm{SD}}=5.3)$. Gregorc reported mean scores of $24.7(\underline{S D}=8.2)$ for the concrete/sequential (CS) type, $22.4(\underline{S D}=6.0)$ for the abstract/sequential type (AS), $26.2(\underline{S D}=7.2$ ) for the abstract/random type, and $23.7(\underline{S D}=7.5)$ for the concrete/random type. Table 9 presents a comparison between the mean score values. 
Table 9

Comparison of Mean Scores of Learning Style Types

\begin{tabular}{lcccc}
\hline Learning Style & \multicolumn{2}{c}{ Gregorc } & $1982(\mathrm{~N}=361)$ & \multicolumn{2}{c}{ Present Study $(\mathrm{N}=96)$} \\
& $\underline{M}$ & $\underline{\mathrm{SD}}$ & $\underline{\mathrm{M}}$ & $\underline{\mathrm{SD}}$ \\
\hline $\mathrm{CS}$ & 24.7 & 8.2 & 25.3 & 5.7 \\
AS & 22.4 & 6.0 & 23.6 & 4.7 \\
AR & 26.2 & 7.2 & 25.7 & 5.2 \\
CR & 23.7 & 7.5 & 25.2 & 5.3 \\
\hline
\end{tabular}


This comparison demonstrates the reliability of the Gregorc tool since the scores of subjects in this current study compare favorably to the scores of the subjects tested by Gregorc. When examining the distribution of the different learning style types it was found that the largest proportion of the subjects $(\underline{n}=54)$ exhibited a "dual" learning style $(56.2 \%)$ rather than a single learning style. Twenty five percent $(\underline{n}=$ 24) were $C R / A R, 17.7 \%(\underline{n}=17)$ were $C S / A S, 7.3 \%(\underline{n}=7)$ were $C S / C R$, $5.2 \%(\underline{n}=5)$ were $C S / A R$, and $2.1 \%(\underline{n}=2)$ were $C R / A S$. The subjects that demonstrated a sole learning style were distributed as follows: $14.6 \%(\underline{n}=14)$ were $C S, 14.6 \%(\underline{n}=14)$ were $C R, 9.4 \%(\underline{n}=9)$ were $A R$, and $5.2 \%(\underline{n}=5)$ were AS. Therefore, four learning styles (CS, CR, CR/AR, and CS/AS) comprised $71.9 \%$ of the sample, with concrete being the predominant dimension. The distributions of the learning style types are summarized in Table 10. 
Table 10

Distribution of Learning Style Types

\begin{tabular}{lrc}
\hline Learning Style & $\underline{\mathrm{n}}$ & $\%$ \\
\hline CS & 14 & $14.6 \%$ \\
CR & 14 & $14.6 \%$ \\
AR & 9 & $9.4 \%$ \\
AS & 5 & $5.2 \%$ \\
CR/AR & 24 & $25.0 \%$ \\
CS/AS & 17 & $17.7 \%$ \\
CS/AR & 6 & $6.3 \%$ \\
CS/AR & 6 & $6.3 \%$ \\
CS/CR & 5 & $5.2 \%$ \\
CR/AS & 2 & $2.3 \%$ \\
\hline
\end{tabular}


Online Instructional Methods Ratings

The methods of online instruction were ranked from highest to lowest mean score. Included were minimum, maximum, mean scores and standard deviations. The rating scores of all instructional methods had at least one maximum score of five, while all (except textbook readings which had a minimum score $=2$ ) had a minimum score of one. Five of the instructional methods had mean scores greater than 4.0. These were threaded discussions $(\underline{M}=4.41)$, individual assignments $(\underline{M}=$ 4.33), e - mail ( $\underline{M}=4.28)$, case studies $(M=4.24)$, and textbook readings $\underline{M}=4.09)$. Only two instructional methods had mean scores greater than 3.50 , which included access to remote data bases $(\underline{M}=3.75)$ and chat room $(\underline{M}=3.59)$. The remaining instructional methods had mean scores ranging from 3.42 (mini lectures) to 2.71 (video assignments) (five respondents chose not to rate the video assignments). The minimum, maximum, mean scores, and standard deviations for all the methods of online instruction are summarized in Table 11. 
Table 11

Online Instructional Methods Ratings

\begin{tabular}{lccccc}
\hline Instructional Method & $\underline{N}$ & $\begin{array}{c}\text { Minimum } \\
\text { Score }\end{array}$ & $\begin{array}{c}\text { Maximum } \\
\text { Score }\end{array}$ & $\underline{\mathrm{M}}$ & $\underline{\mathrm{SD}}$ \\
\hline Threaded discussion & 96 & 1 & 5 & 4.41 & .901 \\
individual assignments & 96 & 1 & 5 & 4.33 & .777 \\
E-mail & 96 & 1 & 5 & 4.28 & .855 \\
Case studies & 96 & 1 & 5 & 4.24 & .872 \\
Textbook readings & 96 & 2 & 5 & 4.09 & .859 \\
Remote data base & 96 & 1 & 5 & 3.75 & 1.005 \\
Chat rooms & 94 & 1 & 5 & 3.59 & 1.273 \\
Mini-lectures & 96 & 1 & 5 & 3.42 & .991 \\
Video clips & 93 & 1 & 5 & 3.40 & 1.044 \\
Self-assessment & & & & & \\
$\quad$ quizzes & 96 & 1 & 5 & 3.39 & .999 \\
Online exams & 95 & 1 & 5 & 3.35 & 1.128 \\
CD-rom futorials & 95 & 1 & 5 & 3.32 & 1.151 \\
Multimedia & 95 & 1 & 5 & 3.25 & 1.139 \\
Webliography & 96 & 1 & 5 & 3.23 & 1.128 \\
Comp. simulations & 93 & 1 & 5 & 3.22 & .998 \\
E- reserve & 95 & 1 & 5 & 3.15 & 1.052 \\
Web site evaluation & 95 & 1 & 5 & 3.14 & 1.058 \\
Mandated number & & & & & \\
$\quad$ of assignments & 96 & 1 & 5 & 3.09 & 1.369 \\
E-journals & 95 & 1 & 5 & 2.89 & 1.267 \\
Group activities & 95 & 1 & 5 & 2.81 & 1.291 \\
Video assignments & 91 & 1 & 5 & 2.71 & 1.003 \\
\hline
\end{tabular}




\section{Learning Styles and Methods of Online Instruction Correlations}

In order to determine if a relationship existed between the learning styles and the methods of online instruction, Pearson - product moment correlation coefficients were calculated for each single learning style and method of online instruction. Coefficients were also calculated for the two dual learning styles CR/AR and CS/AS. The statistic was not calculated for the other dual learning styles (CR/AS, CS/AR, and CS/CR) as the low frequency of these styles would render the value statistically insignificant. Several positive correlations were found between specific learning styles and the methods of online instruction. A moderate positive correlation $(r=.562, p<.05)$ was found between the CS learning style and e-mail. A strong negative correlation $(r=-.743, p<.01)$ was found between the $C R$ style and online exams. Three very strong negative correlations were observed for the AS learning style. These were found regarding E-journals, $(r=-$ $.918, \mathrm{p}<.05)$, use of multimedia $(r=-.984, \mathrm{p}<.01)$, and video clips $(\mathrm{r}=-$ $.976, p<.011$. One very strong positive correlation was also observed for the AS type and computer simulations, which yielded a correlation coefficient of $.994(p<.01)$. For the AR learning style, two strong positive correlations were found between the learning style and mandated number of assignments $(r=.787, p<.05)$ and e-mail $(r=.754, p<.05)$. For 
the dual styles, no significant correlation was found for the CR/AR learning style, however four positive correlations were found for the CS/AS learning style. Self-assessment quizzes demonstrated a high positive correlation $(r=.712, p<.01)$ while moderate correlations were observed at the $p<.05$ level of significance. These were video clips ( $r=$ $.596)$, chat rooms $(r=.556)$, and group activities $(r=.485)$. All Pearsonproduct moment correlation coefficients calculated are shown in Table 12. 
Table 12

Pearson-product Moment Correlation Coefficients for Learning Styles

and Online Instructional Methods

\begin{tabular}{|c|c|c|c|c|c|c|}
\hline Instructional Method & $\mathrm{CS}$ & $C R$ & AS & $A R$ & CR/AR & CS/AS \\
\hline Textbook reading & .363 & -.213 & .688 & -.087 & .343 & -.013 \\
\hline E-journal & .017 & -.302 & $-.918^{*}$ & .287 & -.211 & .119 \\
\hline E- reserve & -.230 & .031 & .355 & .403 & 159 & .033 \\
\hline Multimedia & -.344 & .324 & $-.984^{* *}$ & .108 & -.039 & .044 \\
\hline Remote data base & .045 & -.174 & .507 & .184 & -.133 & .226 \\
\hline Mini lectures & .513 & .387 & .338 & -.269 & -.174 & .227 \\
\hline Chat rooms & .412 & .137 & .355 & .524 & .049 & $.556^{*}$ \\
\hline Threaded discussions & .473 & .303 & .384 & .296 & .055 & .237 \\
\hline E-mail & $.562^{*}$ & -.214 & .486 & $.754^{*}$ & .087 & -.066 \\
\hline Mandated \# of assignments & .465 & -.067 & .740 & $.787^{*}$ & .034 & .047 \\
\hline Group activities & -.145 & -.070 & -.237 & .137 & .055 & $.485^{*}$ \\
\hline Individual assignment & .286 & -.113 & .628 & -.291 & -.029 & -.082 \\
\hline Webliography & .235 & -.311 & -.567 & .055 & -.126 & -.104 \\
\hline Web site evaluation & .231 & -.210 & -.748 & -.250 & -.253 & .120 \\
\hline Self-assessment quizzes & .209 & -.391 & .217 & -.022 & 107 & $.712^{* *}$ \\
\hline Online exams & .216 & $-.743^{* *}$ & .459 & -.022 & .196 & -.072 \\
\hline Computer simulations & .076 & -.159 & $.994^{* *}$ & -.238 & -.020 & .245 \\
\hline Case studies & .147 & -.365 & .281 & $.751^{*}$ & -.145 & -.299 \\
\hline Video clips & 102 & -.306 & $-.976^{* *}$ & .277 & -.136 & $.596^{*}$ \\
\hline Video assignments & -.042 & .409 & -.662 & .569 & -.170 & -.089 \\
\hline CD-rom tutorial & -.017 & -.307 & -.841 & -.084 & .203 & .095 \\
\hline
\end{tabular}


Principal components analysis of the online instructional methods resulted in six extracted factors that accounted for $50 \%$ of the variance. Factor I consisted of those online instructional methods that emphasized online activities such as e-journals, e-reserve, multimedia presentations and mini-lectures. This factor is labeled Factor I: Online Instructional Methods. Factor II, labeled Communication Instructional Methods, consisted of threaded discussions and e-mail. Factor III, Analysis Instructional Methods, consisted of webliography postings, and web-site evaluations. Factor IV, Visual Instructional Methods, contained CD-ROM activities and video clips. Factor V, Individual Instructional Methods, stressed individual work such as textbook readings and case studies. Factor VI was labeled Assessment as this factor consisted of online quizzes. The rotated loading factor matrix is given in Table 13. 
Table 13

Rotated Loading Factor Matrix for Six Extracted Factors

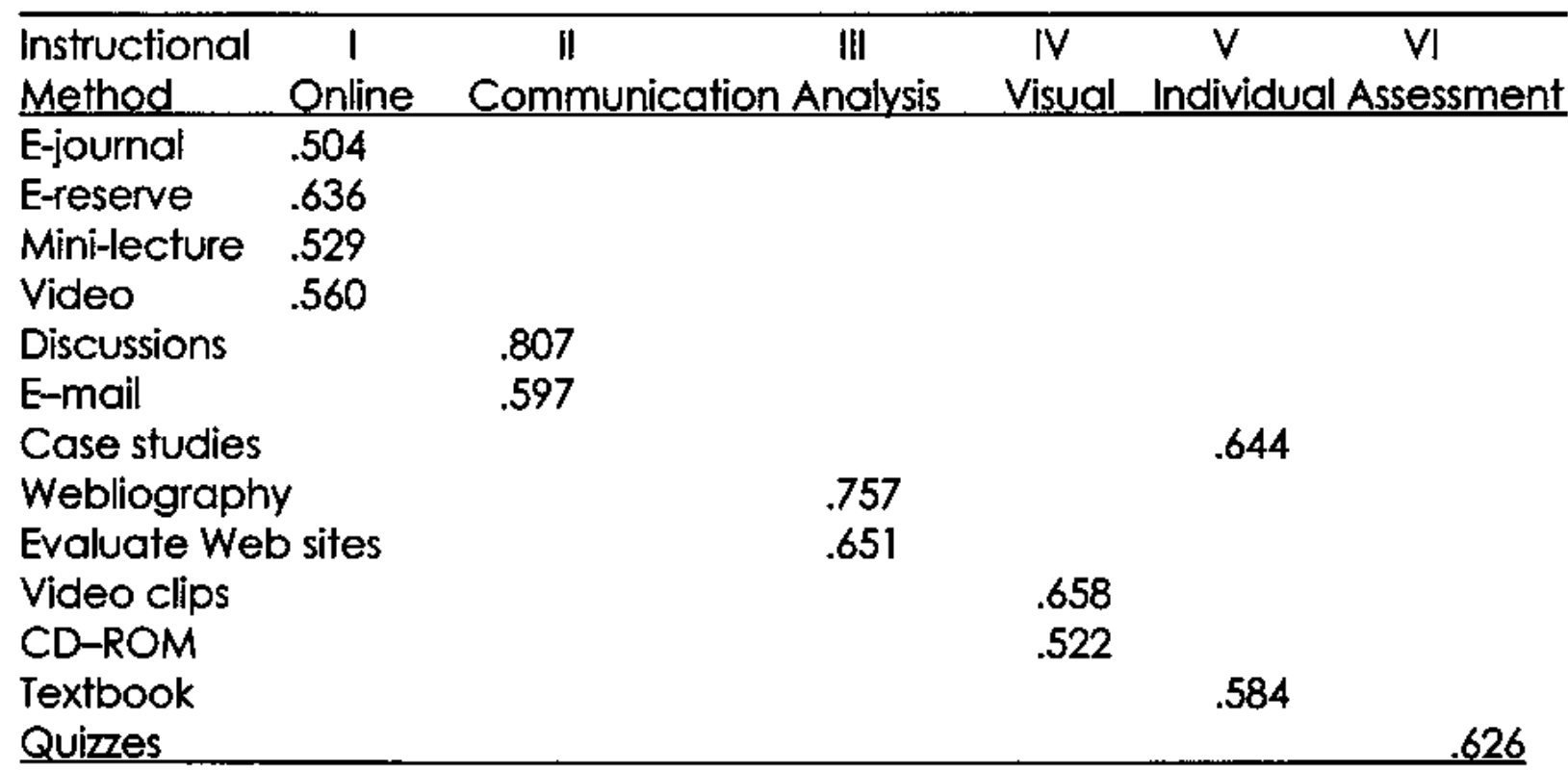


Pearson-product moment correlations were calculated for the six factors and the following learning styles scores: CS, CR, AS, AR, CR/AR, and CS/AS. Correlation coefficients were not calculated for the remaining dual learning styles (CR/AS, CS/AR, and CS/CR) since the low frequencies would render any correlation found to be statistically insignificant. Three correlations were found at the $p<.05$ level of significance. A moderate positive correlation was found between the CR learning style and Factor Ill, Analysis instructional Methods, ( $r=.586)$ while a negative moderate correlation was found between the same learning style, $C R$, and Factor $V$, Individual Instructional Methods ( $r=$ .635). A very high negative correlation was found between the AS learning style and Factor $I$, online instructional methods, $(r=-.983)$. The Pearson - product correlation coefficients for the six factors and the six learning styles are shown in Table 14. 
Table 14

Pearson-product Moment Correlation Coefficients for Learning Styles and Factors

\begin{tabular}{llccccc}
\hline $\begin{array}{l}\text { Learning } \\
\text { Style }\end{array}$ & $\begin{array}{c}\mathrm{I} \\
\text { Online }\end{array}$ & $\begin{array}{c}\text { II } \\
\text { Communication }\end{array}$ & $\begin{array}{c}\text { III } \\
\text { Analysis }\end{array}$ & $\begin{array}{c}\text { IV } \\
\text { Visual }\end{array}$ & $\begin{array}{c}\text { V } \\
\text { Individual }\end{array}$ & $\begin{array}{c}\text { VI } \\
\text { Assessment }\end{array}$ \\
\hline CS & -.240 & .373 & .217 & -.118 & -.286. & .153 \\
CR & .448 & .179 & $.586^{*}$ & -.229 & $-.635^{*}$ & -.557 \\
AS & $-.983^{*}$ & .272 & -.667 & -.089 & .473 & .753 \\
AR & .328 & .538 & -.034 & .135 & .484 & -.219 \\
CR/AR & .062 & -.177 & -.019 & -.024 & .450 & .272 \\
CS/AS & -.073 & .408 & -.094 & .221 & -.452 & .515 \\
\hline
\end{tabular}

${ }^{*}$ Correlation is significant at $p<.05$ (two-tailed) 


\section{CHAPTER V}

DISCUSSION

\section{Respondent Demographics}

The results of the survey revealed that the subjects in this sample represent a mature, returning adult learner with a significant amount of experience with the online learning environment. The respondent demographics also correspond to those found in other studies that had significantly larger samples. In a doctoral dissertation concerning satisfaction with the online services, Ullyat (2003) surveyed 204 students enrolled in the graduate programs at SWW and it was found that $67 \%$ of the respondents were female and that $92.9 \%$ rated themselves as intermediate or advanced computer users, which are similar to the findings in this study. In addition, $75 \%$ of the respondents stated that they were enrolled in their respective programs greater than four months and $94.9 \%$ indicated that their degree program met their expectations. Swan et al. (2000) also found that of the students they surveyed $(N=1,406)$ the majority of the students were female $(67 \%)$ with $54 \%$ of the subjects in the $26-45$ age group and that $88 \%$ rating themselves as having average to high-level computer skills. Therefore, in spite of the small sample size in this current study, the group 
compares favorably with other online learning communities that have been studied.

The Online Learning Experience

The degree of satisfaction with the online learning experience corresponds to previous data. Swan et al. $(2000)$ reported that $91 \%$ of subjects were satisfied or very satisfied with online learning and $85 \%$ felt that computer technology had a positive effect on their learning.

The findings of this study indicate that students cite convenience as the primary factor for enrolling in an online course. The asynchronous learning environment tends to enhance this convenience. In the asynchronous environment, students are able to log-on when it is most convenient, based on work schedule or family commitments. Given their average age and their graduate-level status, it might be assumed that these are working adults with considerable commitments and time constraints. Consequently, learning must occur at a convenient time. The flexibility provided by asynchronous online courses allows a student to log - on at the most opportune time. These findings are consistent with and support the work of other researchers (Andrusyszyn, 2001: Swan et al., 2000). 
The First Research Question

\section{Learning Styles}

A dual learning style, i.e., being comfortable in two of the bipolar dimensions defined by Gregorc, ( $n=54,56.2 \%$ ) was demonstrated by the subjects in this study and support the findings reported by Olson and Scanlan (2002), and Seidel and England (1997). The learning styles exhibited by these subjects indicate that they are adaptable in their learning. Specifically, they can be structured and practical, while being logical and analytical problem solvers and social. Therefore, the findings of this study do not support the hypothesis that the dominant learning style of graduate students enrolled in online education is a single predominant learning style. This also provides the answer to the first research question: i.e., that the dominant learning style that emerges from students enrolled in graduate online courses is a dual learning style with the most frequent being the CR/AR dual style at $25 \%$. While there is limited data in the literature regarding dual learning styles, it has been suggested (Harasym 1995a, 1995b) that the ability to think in a logical fashion, and the ability to order regardless of the abstract dimension becomes the prime learning style. Interestingly, those studies examined students enrolled in nursing and allied health professions, and may reflect the sequential method of thinking required in those 
health professions. In this study, the fact that $25 \%$ of these subjects exhibited the CR/AR style indicates that they are problem solvers who are social in nature. In addition, they are more likely to prefer computer use and think for themselves. However, they would also be more comfortable in a group environment that is personalized. This may also relate to the independent nature of the asynchronous online environment, the high degree of interaction preferred by the subjects, and the types of programs in which they are enrolled, and their professional backgrounds.

\section{The Second Research Question}

Preferences for Online Instructional Methods

In order to determine if a relationship exists between learning styles and the method of instruction, the answer to the second research question must be considered. Is there a preference for specific online instructional methods? Clearly, those instructional methods that emphasized interaction and convenience were rated highly by the subjects as most beneficial to online learning. The preferred methods indicate that the subjects felt that the greatest amount of learning occurred with a mixture of discussion, allowing for the sharing of ideas and the fostering of a learning community. These preferences are 
coupled with a strong predisposition for individual work such as assignments, reading, and case studies. These results contradict Andrusyszyn (2001) who found that students did not prefer one single online instructional method to another. It should be noted that these preferences correspond to the high degree of program satisfaction. The more interactive the pedagogy utilized, the greater the feeling of having learned the material. In addition, the subjects are then better able to apply or interpret the material in a written assignment or case study analysis. Conversely, the subjects expressed that there were learning activities that were not as beneficial to online learning, such as e-journals, group activities, and video assignments. Perhaps these types of activities are construed as "busy work" and do not yield the greatest possible learning. In addition, the responses indicated that the subjects were very familiar with the methods of online instruction presented in the survey. The lower rating of the video assignments suggests that the subjects may not have had any experience with the use of that instructional method. Clearly, the respondents are interested in a pedagogical methodology that yields the greatest amount of learning in the allotted time frame. The ratings of these instructional methods may also correspond to the primary reason online learning was chosen. i.e., convenience. It appears that the subjects would rather spend their 
time learning from each other and applying their new knowledge in a meaningful application rather than writing a narrative e-journal. In discussing the types of instructional methodologies preferred, the results of this study support previous research. Finally, SLN research (Swan ef al., 2000), as well as that of Jian and Ting (1998), revealed that students preferred those methods that provided the most significant amount of interaction. Students prefer a high degree of instructor interaction, as well as meaningful interactions with peers. The implication for course design is evident. Online courses should be designed to include those pedagogical methods that provide the highest degree of interaction without sacrificing the learning objectives that have been established for the course.

Learning Styles and Online Instructional Methods

\section{The Third Research Question}

The third and final research question was to determine if there is a relationship between the subjects' learning style and preferred method of instruction. Due to the sample size represented by the various learning styles, it is important to note that these correlations do not represent a cause and effect relationship, but are more indicative of trends in the correlation of preferred method of online instruction with 
learning styles. Any correlation in a sample size less than 10 must be interpreted with extreme caution, as this sample size would be considered quite small.

The correlations that were noted did not necessarily agree with the personality attributes ascribed to that particular learning style. First, the concrete/sequential $(C S)(n=14)$ learners displayed a moderate correlation with the use of e-mail $(r=.562, p<.05)$. This finding does not appear to fit in with the personality type of the CS learner, as described by Gregorc, who is structured and practical. These findings may reflect the "results oriented" nature of the CS personality or the ability of the individuals to go beyond the confines of a particular learning style. If the definition is expanded, one may conclude that e-mail is also indicative of the CS personality since e-mail is concrete, and a very practical, organized, method of communication. The concrete/random learners displayed a strong negative correlation $(r$ = $.743, p<.05)$ with online examinations. This does correlate with their personality type as problem-solvers and one who learns by discovery, who would prefer problem-based learning and experimental instructional methods. However, if we extend the Gregorc typology, online learning may represent a form of experimental learning that would appeal to the concrete/random learner. The group displaying 
the dual learning style of concrete/sequential-abstract/sequential (CS/AS) had several positive correlations ranging from moderate to high. The methods consisted of chat rooms $(r=.556, p<.05)$, group assignments $(r=.485, p<.05)$, quizzes $(r=.712, p<.001)$, and video clips $(r=.596, p<.05)$. This strong correlation with self-assessment quizzes matches the abstract/sequential learners' predilection for formal testing, while the correlation with video clip viewing and group assignments seems to be a better match with the abstract/random type. However, if video clips and group assignments are viewed as the demonstration of practical lessons, step-by-step directions, and the direct application for problem solving, then the relationship is an appropriate match between learning style and preferred online instructional method.

While the principal components analysis yielded several correlations, the same precaution must be taken when interpreting these findings because of the small sample size. There were moderate negative correlations in those with the concrete/random $(\underline{n}=14)$ learning style and Factor III Analysis (webliography and web-site evaluation) $(r=-.585, p<.05)$, and Factor $V$ Individual (textbook reading and case studies $)(r=-.635, p<.05)$. These results seem contradictory to the traits ascribed to the concrete/random style. 
These individuals usually accept challenges and enjoy investigation and problem solving, although the exploration of case studies may appeal to these learners. Evaluation of web sites would seem to appeal to these types of learners. There were also some marginal correlations for the concrete/random-abstract/random $(C R / A R)$ group $(\underline{n}=24)$ and the concrete/sequential-abstract/sequential (CS/AS) group ( $\underline{n}=17$ ). The CR/AR group had a moderate correlation $(r=.450, p=.053)$ with Factor $V$ Individual (textbook reading and case studies). This corresponds more to the CR personality, who indeed prefers individual work. The CS/AS group displayed a marginal moderate correlation $(r=.515, p=.059)$ with Factor VI Assessment (online quizzes). This corresponds to the attributes ascribed to the AS learning type and the need for formal testing.

The incomplete correlation between all of the learning styles and all of the preferred method of instruction, as exhibited by the correlations found, may be due to the nature of the learning styles instrument and the manner in which it is completed. Although the validity and reliability of the Gregorc Learning Styles Delineator was established in the review of the literature, and was determined to be a valid and reliable tool, it was noted that the ipsative rankings required by all learning style instruments (Ruble \& Stout, 1994) might help to 
explain the statistical incongruities. The rating of the word groupings with self as the reference point suggests that this mature group of learners has "learned to learn", i.e., they have become strategic learners.

The fact that this group is a mature group with a significant amount of experience with online learning might explain the observed discrepancies with the relationships between learning styles and the preferred methods of online instruction. This group's familiarity with the instructional methods may have allowed them to transcend learning style preferences and they have stretched their style to accommodate the types of activities encountered in the online environment. This stretch may have also been influenced by the convenience factor as evidenced by the preferred log-on times and the strong preference for the asynchronous environment. These students want to complete the assignments and maximize their learning in the time dictated by their daily routine. In addition, as graduate students, this group may display a higher degree of motivation in order to achieve advancement and professional success.

An alternative explanation for the lack of consistency in the correlations can be found in another learning theory that is not grounded in Jungian philosophy of personality, but in motivational 
theory. Atherton (2003a) discusses that learning occurs because of extrinsic factors and/or intrinsic motivational factors such as job success, a sense of personal achievement, or to gain a reward such as a pay increase. Incorporating this motivational approach, Atherton (2003b) builds upon the work of Biggs and Entwistle, and proposes that learning can be described as "deep" or "surface" learning. Surface learning is primarily motivated by fear of failure. The student is able to determine what is required by the instructor in order to receive a good grade and, therefore, achieve academic success. In contrast to surface learning, deep learning relates previous knowledge to current course content and the student is able to relate theory to practice. Atherton (2003b) also argues that strategic learning is actually an organized form of surface learning where the motivation is the need to achieve good grades, or some other motivational factor.

Therefore, the high degree of communication, convenience and individuality, in conjunction with motivational factors, may help explain the results of this study. This is exemplified by the anecdotal comments made by the students. When the students were invited to comment on any aspect of the online learning experience, the majority of the comments echoed the results discussed. One student stated that, "Communicating regularly with my faculty and cohort is beneficial 
even when not directly related to content. The most beneficial instructional method is the constant interaction and feedback from the professor. She makes the class come alive." Another student commented that: "l like the threaded discussions about current trends (reality in the workplace), it's not just based on textbooks." These students have indicated that they thrive and learn from the interaction and feedback, not just from professors, but from peers as well. 


\section{CHAPTER VI}

\section{SUMMARY AND CONCLUSIONS}

This study attempted to determine if there was a dominant learning style among online learners, to discover a preference for a particular pedagogical methodology, and to determine if a relationship exists between any learning style and a pedagogical method. While the CS and CR learning styles emerged as the most frequent single learning style, the CR/AR and CS/AS dual learning styles were the dominant learning style, and that there were strong preferences concerning instructional methods, such as threaded discussions and individual assignments respectively. Data analysis also revealed several significant positive or negative relationships between learning styles and instructional methods: the CS style exhibited a positive relationship to email use, the CR type revealed a negative correlation to online examinations, while the AS type demonstrated a positive relationship to computer simulations, but a negative one to the use of multimedia. Those students exhibiting the dual learning style CR/AS demonstrated a statistically significant negative correlation for self-assessment quizzes but a positive correlation for video clips. This dichotomy may be attributed to the fact that the subjects $(\underline{N}=96)$ were all graduate 


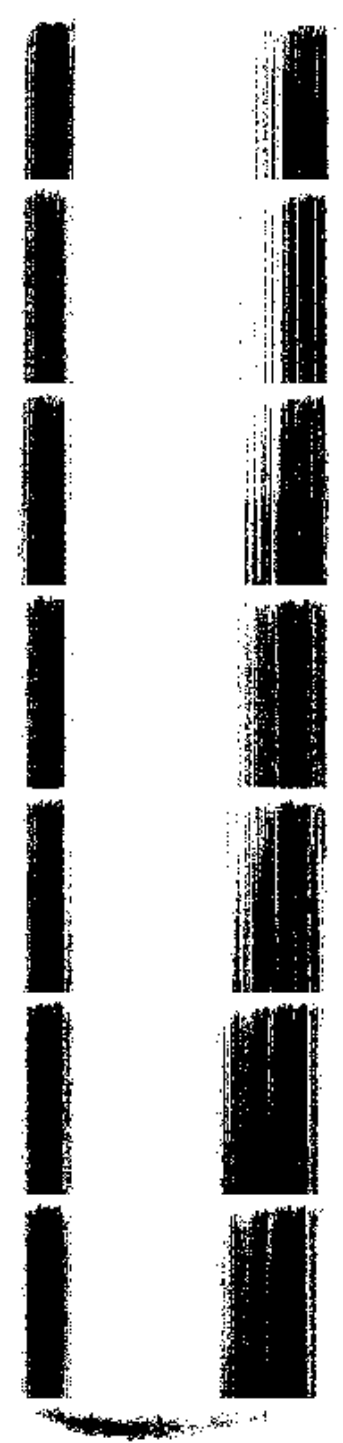

students committed to the completion of an advanced degree within their chosen profession and therefore, are driven by some intrinsic or extrinsic motivational factors. These types of individuals are usually goal-oriented with motivational skills that are conducive to the completion of a degree program whether the format is online or traditional. The results may be quite different if undergraduate subjects were surveyed and should be the subject of a future study.

In the examination of the group demographics, some significant findings emerged as this group, a mature learning community with 
generalizability of the study. This would be true if the goal of this study was to establish any cause-effect relationships. However, the data can be interpreted as being indicative of trends in the learning styles and preferences for instructional methods. A large number of responses had to be eliminated, however the remaining data displayed a very strong response for course satisfaction, the online educational experience, and rating of online instructional methods. These areas received such a high positive response that a larger sample would, one may conclude, also have yielded the same high degree of satisfaction. It is also probable that a larger sample would reveal that the dual learning style is the dominant learning style as well. The sample size of this current study would be too small if inferences and conclusions were to be made between gender, student age, or major, and any of the research questions.

The results of this study are informative for researchers concerned with online instruction as it provides definitive answers to the questions of preferred methods of online instruction. This study confirms the results found by Andrusyszyn (2001) and Swan (2000) that students enrolled in online courses want to learn at a convenient time. Educators involved with the design of online courses should consider the asynchronous environment as the primary environment to afford the students a wide 
time span to access the course materials and complete the assignments. Because of the strong preference for the asynchronous environment, educators should avoid or limit mandated log-ons and mandated number of postings or assignments. However, convenience should not be confused with ease and the learning objectives should not be compromised. Textbook readings, case studies, and individual assignments allow students to digest and apply the course material, while threaded discussions, characteristic of online learning, foster a learning community for students to discuss the material, exchange ideas, and learn from each other. Additionally, the instructor is able to ascertain the level of learning by monitoring students' responses over time. Therefore, it is important to keep the course as interactive as possible without sacrificing the quality of the instruction or the educational objectives of the course.

The results of this study also reaffirmed the findings of Olson and Scantan (2002) and Seidel and England (1997), who reported the dual learning style as the dominant learning style in their subjects, respectively. This may reflect that today's learners are more flexible, stretch their learning style to accommodate a variety of instructional methods, or transcend those instructional methods that are comfortable. 
The need for additional research in this area remains. While this study revealed significant results among experienced online graduate students, research should also involve those students who have little or no online course experience or those who have dropped out of online programs. Would such a study reveal a dominant learning style present in those individuals that would not be conducive to online learning? Would it become evident that a factor in the nature of online learning could account for the attrition? Additionally, if a sample of undergraduate students enrolled in their first online course was studied. it may limit the possible influence of motivation on the results.

Therefore, a subsequent study using a larger sample size, or a replication of this study utilizing a different sample may support or strengthen the results presented here. For example, a survey of students enrolled in a synchronous environment could be compared to those enrolled in an asynchronous environment. Would the preferred method of online instruction be similar between the two groups?

Perhaps, a study investigating online education and the role of motivational influences or, the relationship between surface learning and deep learning le.g. , such as giving the instructor whatever is necessary to succeed in the course in contrast to incorporating critical thinking and transfer of knowledge, respectively.) should be explored. 
Coupled with learning styles and preferred methods of online instructional methods research, online course design and course management could be enhanced to maximize the learning experience. Because of the predicted increase in the numbers of students that will be involved in online learning (Carnavale, 2002), research should continue to ascertain the motivation and learning dynamics of all students.

In conclusion, the correlations between the learning styles, and the methods of instructional methods that suit those styles, were examined within the definitions outlined by Gregorc. While no single dominant learning style emerged, strong preferences for online instructional methods were found. The principal component analysis yielded six groupings of instructional methods, and corresponding relationships. Educators must be challenged beyond the definitions established in the pre-online era, identify the learning styles of online learners, and analyze the types of instructional methods that are unique to online learning. The nature of online learning and the instructional methods used are new. Therefore, old constructs must be reexamined and redefined to explain this new pedagogy. This is a new road that must be paved to optimize the educational process and this study has begun that task. 


\section{References}

Andrews, S., DiGangi, S.A., Winograd, D., Jannasch-Pennell, A.\& Yu, C. (1999). Designing online instruction using multidisciplinary approaches. Proceedings of selected research and development papers presented at the National Convention of the Association for Educational Communications and Technology, Houston, Texas, February 10-14, 1999. Retrieved October 23, 2002, from EBSCOhost.

Andrusyszyn, M. (2001). Nurse practitioner preferences for distance education methods related to learning style, course content, and achievement. Journal of Nursing Education, 40(4), 163. Retrieved October 15, 2002, from Proquest.

Atherton, J.S. (2003). Learning and teaching: motivation to leam. http://www.dmu.ac.uk/-jamesa/learning/motivlrn.htm. Accessed December 30, 2003.

Atherton, J.S. (2003). Learning and teaching: deep and surface learning. http://www.dmu.ac.uk/ jamesa/learning/deepsurf.htm. Accessed December 30, 2003.

$\mathrm{Bi}, \mathrm{X} .(2000)$. Instructional design attributes of a web-based course. Presented at WebNet 2000 World Conference on the WWW and Internet Proceedings, San Antonio, Texas. Retrieved October 23, 2002, from EBSCOhost.

Bokoros, M.A.\& Goldstein, M.B., Sweeney, M.M. (1992). Common factors in five measures of cognitive style. Current Psychological Research Review, 11, 99 - 109.

Biggs, J.B. (1978). Individual differences in study processes and the quality of learning outcomes. Higher Education, 8, 381- 394.

Brown, B.L. (1998). Learning styles and vocational education practice. Proctice Applications Brief, ERIC/ACVE. Retrieved on October 12, 2003 from ttp://ericacve.org/docgen.asp?tbl=pab\&|D=74. 
Bullen, M. (1998). Participation and critical thinking in university distance education. Journal of Distance Education, 13(2), 1 - 32 . Retrieved October 23, 2002, from EBSCOhost.

Butler, K. (1988), Learning Styles. Learning, 88, $30-34$.

Campbell, J. (Ed.) (1971). The Portable Jung. (R.F.C. Hull, Trans.), NY: The Viking Press.

Canfield, A.A. \& Lafferty, J.C. (1974). Learning Styles Inventory, Birmingham, Ml: Humanics Media.

Carnavale, D. (2002, July 19). Stronger students benefit more from online course, Texas study says. Chronicle of Higher Education, 48(45), A30.

Cornwell, J.M., Manfredo, P.A., \& Dunlap, W.P. (1991). Factor analysis of the 1985 revision of Kolb's learning style inventory. Educational and Psychological Measurement, 51, 455- 462.

Delahoussaye, $M$. (2002). The perfect learner: an expert debate on learning styles. Training, 39(5), 28 - 36. Retrieved October 15, 2002, from Proquest.

Diaz, D.P. \& Cartnal, R.B. (1999). Students' learning styles in two classes: online distance learning and equivalent on-campus. College Teaching, 47(4), 130 - 135. Retrieved October 23, 2002, from EBSCOhost.

Dictionary of Student Outcome Assessment (2003). http://perple.jmu.edu/yangsx/alphaterm.asp?firstletter=1. Accessed December 29, 2003.

Drummond R.\& Stoddard, A. (1992). Learning style and personality type. Perception Motor Skills, 75, $99-104$.

Eide, B.J., Geiger, M.A., \& Schwartz, B.N. (2001). The Canfield learning styles inventory: an assessment of its usefulness in accounting education research. Issues in Accounting Education, 16, 3, 341 - 365 . Retrieved October 15, 2002, from Proquest. 
Entwistle, N.J., Hanley, M. \& Ratcliffe G. (1979). Approaches to learning and levels of understanding. British Journal of Education Resources, 5, $99-114$.

Ginter, E., Brown, S., Scalise, J.\& Ripley, W. (1989). Perceptual learning styles: their links to academic performance, sex, age, and academic standing. Perception Motor Skills, 68,1091- 1094.

Grasha, A. (1996). Teaching with style: a practical guide to enhancing leaming by understanding teaching and learning styles. Pittsburgh, PA: Alliance Publishers.

Gregorc, A.F.(1982). Gregorc Style Delineator: Development, technical and administrative manual. Maynard, MA: Gabriel Systems Inc.

Gregorc, A.F. (1984). Style as a symptom: a phenomenological perspective. Theory Practice, 23, 51 - 55.

Gregorc, A.F.\& Butler, K.A. (1984). Learning is a matter of style. Vocational Education, 59, 27 - 29.

Haislett, J. J., Hughes, R.B., Atkinson, G. \& Williams, C.L., (1993). Success in baccalaureate nursing programs: a matter of accommodation? Journal of Nursing Education, 32(2), 64 - 70.

Harasym, P., Leong, E, Lucier, G.\& Lorsheider, F. (1995) Gregorc learning styles and achievement in anatomy and physiology. Advances in Physiology Education, 13, 61 - 65 .

Harasym, P., Leong, E., Juschka, B., Lucier, G. \& Lorsheider, F. (1995) Myer-Briggs psychological type and achievement in anatomy and physiology. Advances in Physiology Education, 13, 56 - 58.

Hendricson, W.D., Berlocher, W.C.,\& Herbert, R.J. (1987). A four year longitudinal study of dental student learning styles. Journal of Dental Education, 51 (4), 175 - 181.

Hinkle, D.E., Wiersma, W., \& Jurs, S.G. (1998). Applied statistics for the behavioral sciences (4th ed.). Boston, MA: Houghton Mifflin. 
Hutton, S. (1999). Course design strategies-troditional versus online. What works transfers? What doesn't? Presented at the Annual Meeting of the American Association for Adult and Continuing Education, November 1999, Phoenix, Arizona. Retrieved October 23, 2002, from EBSCOhost.

Jiang, M. \& Ting, E., (1998, April). Course design, instruction, and students' behaviors: study of instructional variables and students perceptions of learning. Presented at the Annual Meeting of the American Medical Research Association, San Diego, California. Retrieved October 23, 2002, from EBSCOhost.

Jones, D. (2003, February 11). More students get MBAs online. USA Today, p. 3B. Retrieved March 15, 2003 from lexis - nexis.

Joniak, A.J.\& Isaksen, S.G. (1988). The Gregorc style delineator: Internal consistency and its relation to Kirton's adaptive-innovative distinction. Educational and Psychological Measurement, 48, 1043 1049.

Jöreskog, K.G. \& Sörbom, D. (1989). LISREL 7: A guide to the program and applications (2nd ed.). Chicago, IL: SPSS, inc.

Jung, C.G. (1923). Psychological types. NY: Harcourt, Brace \& Co.

Karuppan, C. (2001). Web-based teaching materials: a user's profile. Internet Research, 11(2), 138-148. Retrieved October 15, 2002, from Proquest.

Katz, N. \& Heimann, N. (1991). Learning style of students and practitioners in five health professions. Occupational Therapy Journal Resources, 11 (4), 238 - 244.

Kingsley, B. (2002, October 10). Online education growing on campuses, Florida State View and Florida Flambeau via University Wire. Retrieved March 15, 2003, from lexis-nexis.

Kolb, D.A. (1976). The Learning Style inventory: technical monual, Boston, MA: McBer and Company. 
Koob, J.J. \& Funk, J. (2002). Kolb's Learning Style inventory: issues of reliability and validity, Research on Social Work Practice. 12(2), 293308. Retrieved October 15, 2002, from Proquest.

Linares, A. (1999). Learning styles of students and faculty in selected health care professions, Journal of Nursing Education, 38, 9, 407-413.

Liow, S.R. \& Betts, M. (1993). Course design in higher education a study of teaching. Studies in Higher Education, 18(1), $65-80$. Retrieved October 23, 2002, from EBSCOhost.

Logan, K. \& Thomas, P. (2002). Learning styles in distance education students learning to program. Presented at the 14th. Workshop of the Psychology of Programming Interest Group, Brunel University, June 2002.

Mehlenbecher, B., Miller, C.R., Covington, D.\& Larsen, J.S. (2000). Active and interactive learning: a comparison of web-based and conventional writing classes. IEEE Transactions on Professional Communication, 43(2), 166-148. Retrieved October 15, 2002, from Proquest.

Myers, J.B., \& McCaulley, M.H. (1985). Manual: a guide to the development of the Myers - Briggs type indicator, Palo Alto, CA: Consulting Psychologists Press.

Nelson, B., Dunn, R., Griggs, S.A., Primavera, L., Fitzpatrick, M., Bacilious, Z., Miller, R. (1993). Effects of learning styles intervention on college students' retention and achievement. Journal of College Student Development, 34, 364-368.

Norris, S.P., \& Ennis, R.H. (1989). Evaluating critical thinking. Pacific Grove, CA: Critical Thinking Press and Software.

O'Brien, T.P. (1990). Construct validation of the Gregorc style delineator: An application of LISREL 7. Educational and Psychological Measurement, 50, 631 - 636 .

Olson, V.G. \& Scanlan, C.L. (2002). Physical therapy students' learning styles and their teaching method and instructional activity preferences. Journal of Physical Therapy Education, 16(2), 24-31. 
Ross, J.L. \& Schulz, R.A. (1999). Can computer-aided instruction accommodate all learners equally? British Journal of Educational Technology, 31, 5-24.

Ruble, T.L. \& Stout, D.E. (1994). A critical assessment of Kolb's learning style inventory. East Lansing, Ml: National Center for Research on Teacher Learning. (ERIC document Reproduction Service No. ED 377 221).

Seidel L. \& England, E.M. (1997). Gregorc's cognitive styles: preferences for instructional and assessment fechniques in college students. Poster presented at the Annual Convention of the American Psychological Association, Washington D.C.

SetonWorldWide (2003). Annual Report. West Orange, NJ: Seton Hall University.

Simon, S. J. (2000). The relationship of learning style and training method to end-user computer satisfaction and computer use: a structural equation model. Information Technology, Learning, and Performance Journal, 18(1), 41 - 59. Retrieved October 15, 2002, from Proquest.

SLN (2000). Suny Learning Network Course Developer Handbook. Albany, NY, SUNY Learning Network,.

SPSS (Version 9.0). (1999). Chicago, IL: SPSS Inc.

Stevens, J. (1996). Applied multivariate statistics for the social sciences (3rd ed.). Mahwah, NJ: Lawrence Erlbaum Associates.

Swan, K. (2001). Virtual interaction: design factors affecting student satisfaction and perceived learning in asynchronous courses. Distance Education, 22(2), 306 - 331. Retrieved October 23, 2002, from EBSCOhost.

Swan, K., Shea, P., Fredericksen, E., Pickett, A.M.\& Pelz, W.E. (2000, October). Course design factors influencing the success of learning. Presented at WebNet 2000 World Conference on the WWW and Internet Proceedings, San Antonio, Texas. Retrieved October 23, 2002. from EBSCOhost. 
Thompson, M.J. (1989). Validation of the Gregorc learning style model. Occupational Education Forum, 40, 34 - 39.

Tsay, M-H., Morgan, G. \& Quick, D. (2000). Predicting students' ratings of the importance of strategies to facilitate self - directed distance learning in Taiwan. Distance Education, 21, 1, 49-65.

Ullyat, D. (2003). Satisfaction of students and administrators toward support systems in online degree programs: a case study. Unpublished doctoral dissertation, Seton Hall University.

Valenta, A., Therriault, D., Dieter \& Mrtek, R. (2001). Identifying student attitudes and learning styles in distance education. JALN, 5(2), $111-127$.

Walts, T. \& Lewis, L. (2003). Distance Education at Degree-granting Postsecondary Institutions. National Center for Educational Statistics, U.S. Department of Education, Washington D.C. Retrieved July 18, 2003 from nces.ed.gov/pubsearch/pubsinfo.asp?pubid 2003017.

www.ecollege.com/products/Products.learn.

www.nces.ed.gov.

www.setonworldwide.net.

www.sin.suny.edu/sIn/public/original.nsf/504ca249c786e20f85256284 006da7ab/bd9a90d415c32956852563f6007a1297\%OpenDocument. 
APPENDIX A

PERMISSION TO SOLICIT SETONWORLDWIDE STUDENTS 


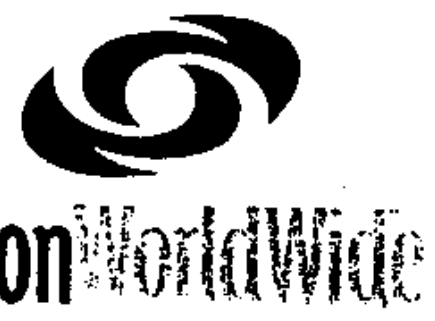

January 30, 2003

To Whom It May Concern: I am writing in support of Thomas Butler's research: Learning Styles and Instructional Methods
in Online Courses.

As the Director of SetonWorldWide, I give Mr. Butler approval to conduct survey research with the graduate students enrolled in SetonWorldWide's online degree programs. He will work with me on the implementation of his instrument and the timing of his data collection.

Sincerely,

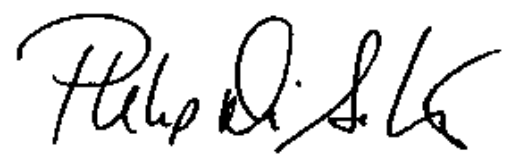

Philip DiSalvio, Ed.D.

Director, SetonWorldWide

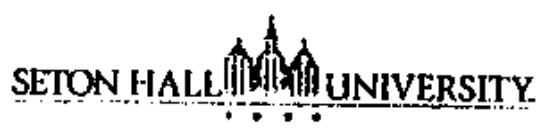

400 South Orange Ave. - South Orange, N1 07079 - Phone: 1-888-5ETON-WW - Fax: 973-761-9325

www.SetonWorldWide.net " SetonWorldWide@shu.edu 
APPENDIX B

IRB APPROVAL LETTER 


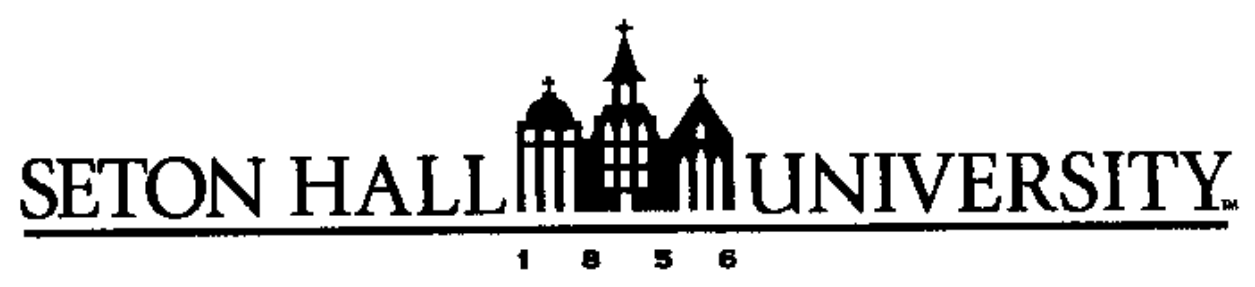

February 27, 2003

Thomas Butler

367 Diamond Spring Rd

Denville, NJ 07834

Dear Mr Butler.

The Seton Hall University Institutional Review Board has reviewed the information you have submitted addressing the concerns for your proposal entitled "Learning Styles and Instructional Methods in Online Courses". Your research protocol is hereby approved as amended through expedited review. The IRB reserves the right to recall the proposal at any time for full review.

Enclosed for your records are the signed Request for Approval form and the stamped original Consent Form. Make copies only of this stamped Consent Form.

The Institutional Review Board approval of your research is valid for a one-year period from the date of this letter. During this time, any changes to the research protocol must be reviewed and approved by the IRB prior to their implementation.

According to federal regulations, continuing review of already approved research is mandated to take place at least 12 months after this initial approval. You will receive communication from the IRB Office for this several months before the anniversary date of your initial approval.

Thank you for your cooperation.

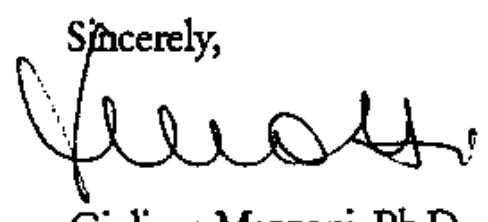

Giuliana Mazzoni, Ph.D.

Associate Professor

Director, Institutional Review Board

cc: Genevieve Pinto-Zipp, Ed.D. 


\section{REQUEST FOR APPROVAL OF RESEARCH, DEMONSTRATION OR RELATED ACTIMTIES WVOLVNG HUWAN SUBJECTS}

\section{Allmaterial must be typed.}

PROJECT TITLE:_L Leaming Styles end Instructional Melthods in On-line Courses

CERTIFICATION STATEMENT:

In making thls application, I(we) certify that I(we) have read and understand the University's policies and procedures goveming research, development, and related activities involving human subjects. I (we) shall comply with the letter and spirit of those policies. l(we) further acknowledge my(our) obligation to (1) obtain written approval of significant deviations from the originally-approved protocol BEFORE making those deviations, and (2) report immediately all adverse effects of the study on the subjects to the Director of the Institutional Review Board, Seton Hall University, South Orange, NJ 07079.

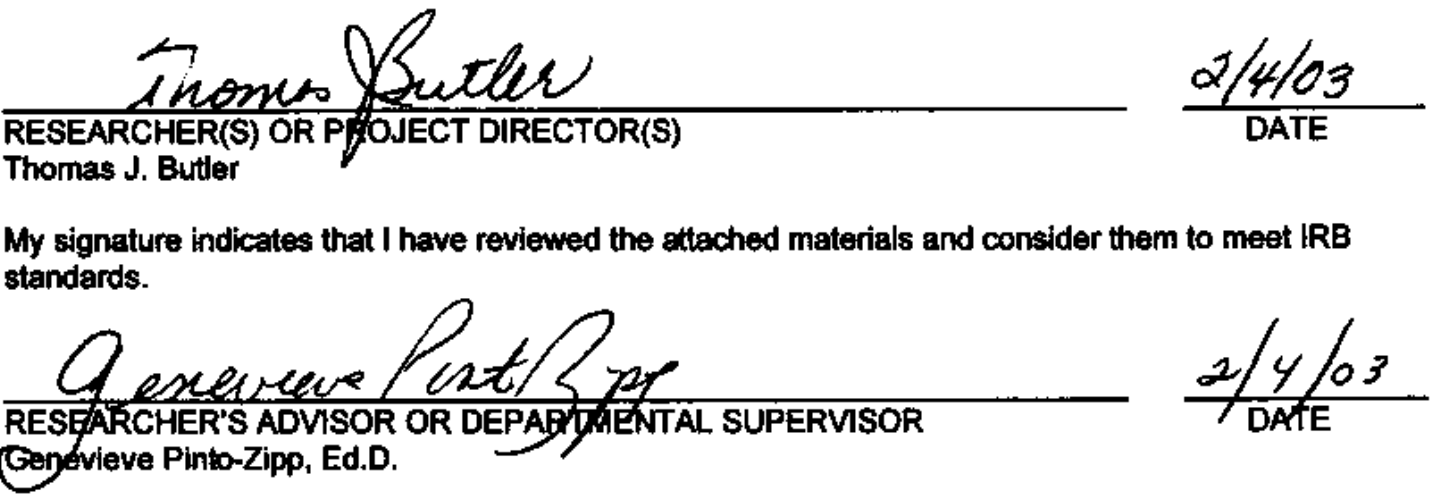

The request for approval submitted by the above researcher(s) was considered by the IRB for Research

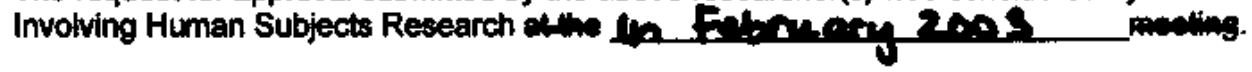

The application was approved $/$ not approved _ by the Committee. Special conditions were were not $\_$set by the IRB. (Any special conditions are described on the reverse side.)

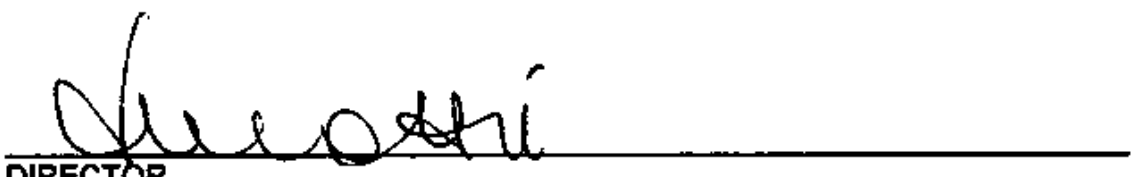

DIRECTOR,

SETON HALL UNIVERSITY INSTITUTIONAL

REVIEW BOARD FOR HUMAN SUBJECTS RESEARCH

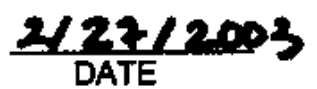

\section{APPROVED}

FEB 272103

IRB 
APPENDIX C

PERMISSION TO USE THE GREGORC LEARNING STYLES DELINEATOR 


\section{RBQUEST POR RIGHT TO PURCDASE AND USE THE GRECORC STYLE DELNBATOR-REYRARCH WDTHON}

I hereby request permission to obtain the Research Edition of the Greponc. Styde Delinentor. In requesting this permission, I do so under the following conditions and certify that:

1. The instrument will be used for bonalide research only. (Not as a substitute for the Regular Edition)

2. I will provlde Dr. Anthony F. Gregorc with an Abstract of my Proposal and/or a Statement of the Problem and Hypotheses.

3. I will not display the Research Edition of the Greaorc Style Dellneator In Its entirety in the body or Appendlx of the study document. A description of the instrument and a specimen column of words are acceptable.

4. Upon completion of the study, I will provide Dr. Gregorc with an Abstract of the results of my indings, and

5. I will administer, Interpret and use the Research Edition of the GreaprcStyle

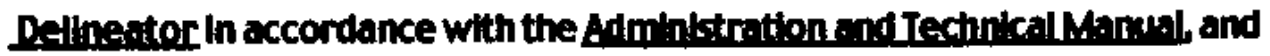
Idews, principles and descriptors in The Mind Stydes Modetitheory.Princlndes and Anpilcretions AnAdult's Guldeto Stvile and the Mind Styles FAOSBook.
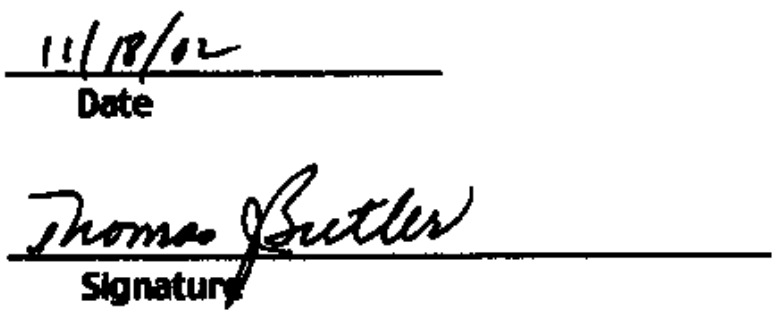

$9 / 1 / 03$

Anticipated Completion Date of Study

NOTE: Please sion and return one copy of this Request form. It must be accompanied with the Abstract of your Proposal. 
APPENDIX D

SOLICITATION LETIER 


\section{SETON HALL艋UUNIVERSITY.}

Dear SetonWorldWide Graduate Student,

My name is Thomas Butler and I am a doctoral candidate at Seton Hall University's School of Graduate Medical Education and am conducting a research project that will culminate in my dissertation

I am interested in knowing if your preferences for some types of online instructional methods are more beneficial than others and whether they relate to your learning style. You are being asked to complete a two-part survey that will take no more than 15 minutes to complete. Part A of the survey will assess your "learning style." Part B will assess the instructional methods you find most beneficial to your learning.

The results of this study may help those involved in online education improve the design of the courses and tailor instructional methods to meet the needs of online learners. Therefore, your feedback is important!

The survey is cataloged according to your SetonWorldWide account login for follow-up purposes only. All responses will be treated confidentially and will in no way be traceable to individual respondents once the survey process has been completed. You have the option to complete the survey now or anytime during the next two weeks. Once you complete the survey, you will not be asked to complete it again. You are also free to not participate. Feel free to print any part of the survey. If you would like to know the results of the survey, please feel free to contact me and I will provide you with the information!

This project has been reviewed and approved by the Seton Hall Review Board for Human Subjects Research. The IRB believes the procedures adequately safeguard the subject's privacy, welfare and rights. The Chairperson of the IRB may be reached at (973) 275 - 2974

Thank you for your help and cooperation!

Thomas J. Butler

Doctoral Candidate

School of Graduate Medical Education

Seton Hall University

\section{APPROVED \\ FEB 272803 \\ IRB \\ SETON HALL UNIVEASITY}


APPENDIXE

INFORMED CONSENT FORM 


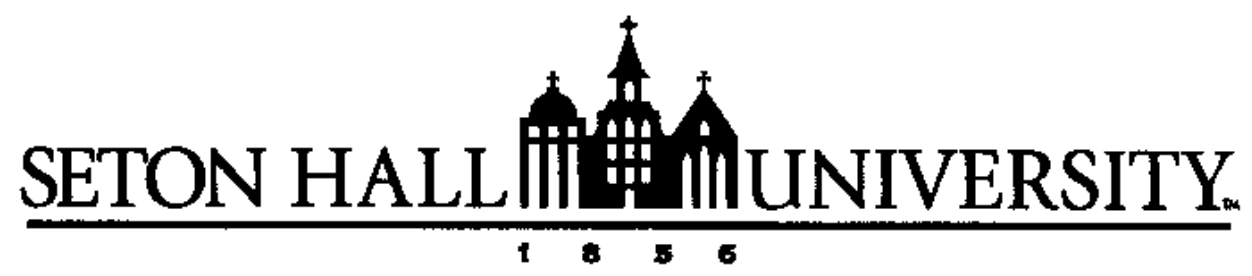

\section{INFORMED CONSENT FORM}

\section{Affiliation}

My name is Thomas Butler and I am a doctoral student at Seton Hall University's School of Graduate Medical Education. I am conducting a research project that will culminate in my dissertation.

\section{Purpose}

The purpose of this letter is to engage your consent and participation in a research study investigating learning styles and the types of instructional activities preferred by students in their online courses.

\section{Methods}

You will be asked to complete a two-part survey. Part A will assess your "learning style." It will be measured using the Gregorc Style Delineator. Part B is a questionnaire that will ask you to rate your preferred method of learning in the online environment. The time required to complete the survey should be no more than 15 minutes.

\section{Voluntary Participation}

Participation in this study is completely voluntary and is not required for completion of the course in which you are enrolled. Refusal to participate or discontinuing participation at any time will involve no penalty or loss of benefits to which you are otherwise entitled. Submission of a completed survey will be accepted as your electronic consent for participation.

\section{Anonymity}

In no way will your identity be solicited or revealed. Your login will only be used to insure that you do not submit multiple surveys. You may print or download a copy of this consent or any other parts of the survey for your records. I will not provide you with a description of your learning style. Therefore you are free to contact me and I will mail you a copy of the scoring rubric so you may personally score your own form.

\section{Confidentiality of Participants}

All surveys are confidential and only the data gathered through the surveys will be released. After the two week survey period, all responses and forms will be removed from the course. There are no identifiers to associate you with your response. All data will remain confidential with the researcher and will only be used in the calculation of statistical data.

\section{Data Storage}

After the data is collected, it will be removed from the course and only the data will be exported to a statistical database. The data will be then securely stored in a locked cabinet with access only to the researcher for a period of three years.

\section{Risk}

There is no risk to participation in this study.

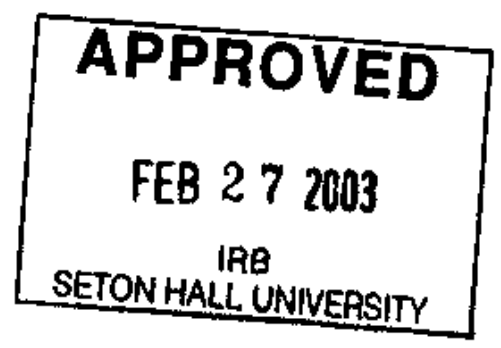




\section{Proposed Beneffit of the Study}

There are no proposed benefits of the study for you. However, the results of this study may help improve the design of online courses and aid instructors in meeting the instructional needs of students based on their learning styles in future courses.

\section{Compensation}

No compensation for participation is provided.

\section{Questions}

Questions regarding the nature of this study or rights of the participants should be directed to:

Mr. Thomas Butler

C/O Seton Hall University

School of Graduate Medical Education

400 South Orange Avenue

South Orange N.J. 07079

973-275-2076

\section{IRB Approval}

This project has been reviewed and approved by the Seton Hall Review Board for Human Subjects

Research. The IRB believes the procedures adequately safeguard the subject's privacy, welfare and rights. The Chairperson of the IRB may be reached at (973) 275 - 2974.

I have read the material above, and any questions I asked have been answered to my satisfaction. I agree to participate in this activity, realizing that I may withdraw without prejudice at any time.

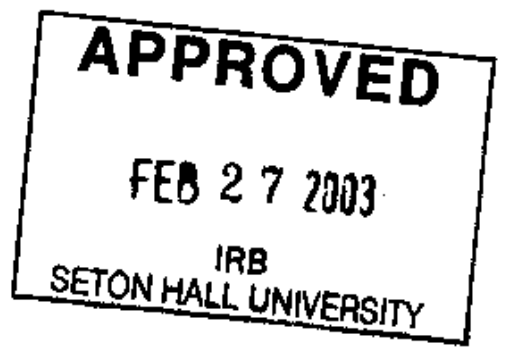


APPENDIX F

SAMPLE OF THE GREGORC LEARNING STYLES DELINEATOR (PART A) 


\section{DIRECTIONS}

Before starting with the word matrix on the next page, carefully read all seven of the following directions and suggestions:

1. Reference Point. You must assess the relative value of the words in each group using your SELF as a reference point: that is, who you are deep down. NOT who you are at home, at work, at school or who you would like to be or feel you ought to be. THE REAL YOU MUST BE THE REFERENCE POINT.

2. Words. The words used in the Cregorc Style Delincator matrix are not parallel in construction nor are ther all adjectives or all nouns. This was done on purpose. Just react to the words as they are presented."

3. Rank. Rank in order the ten sets of four words. Put a " 4 " in the box above the word in each set which is the best and most powerful descriptor of your SELF. Give a " 3 " to the word which is the next most like you, a " 2 " to the next and a "l" to the word which is the least descriptive of your SELF. Each word in a set must have a ranking of $4,3,2$ or 1. No two words in a set can have the same rank.

4 - MOST descriptive of you

1 - LEAST descriptive of you
4. React. To rank the words in a set. react to your first impression. There are no "right" or "wrong" answers. The real, deep-down youl is best revealed through a first impression. Go with it. Analyzing each group will obscure the qualities of SELF smight by the Delineator.

5. Proceed. Continue to rank all ten vertical columns of words, one set at a time.

6. Time. Recommended time for word ranking: 4 minutes.

7. Start. Turn the page and start now.

-For an explanation an how and why thesc words were chosen, sex' the "Denelopment" section of An Adudts Ciside to Style. 


\section{WORD MATRIX}

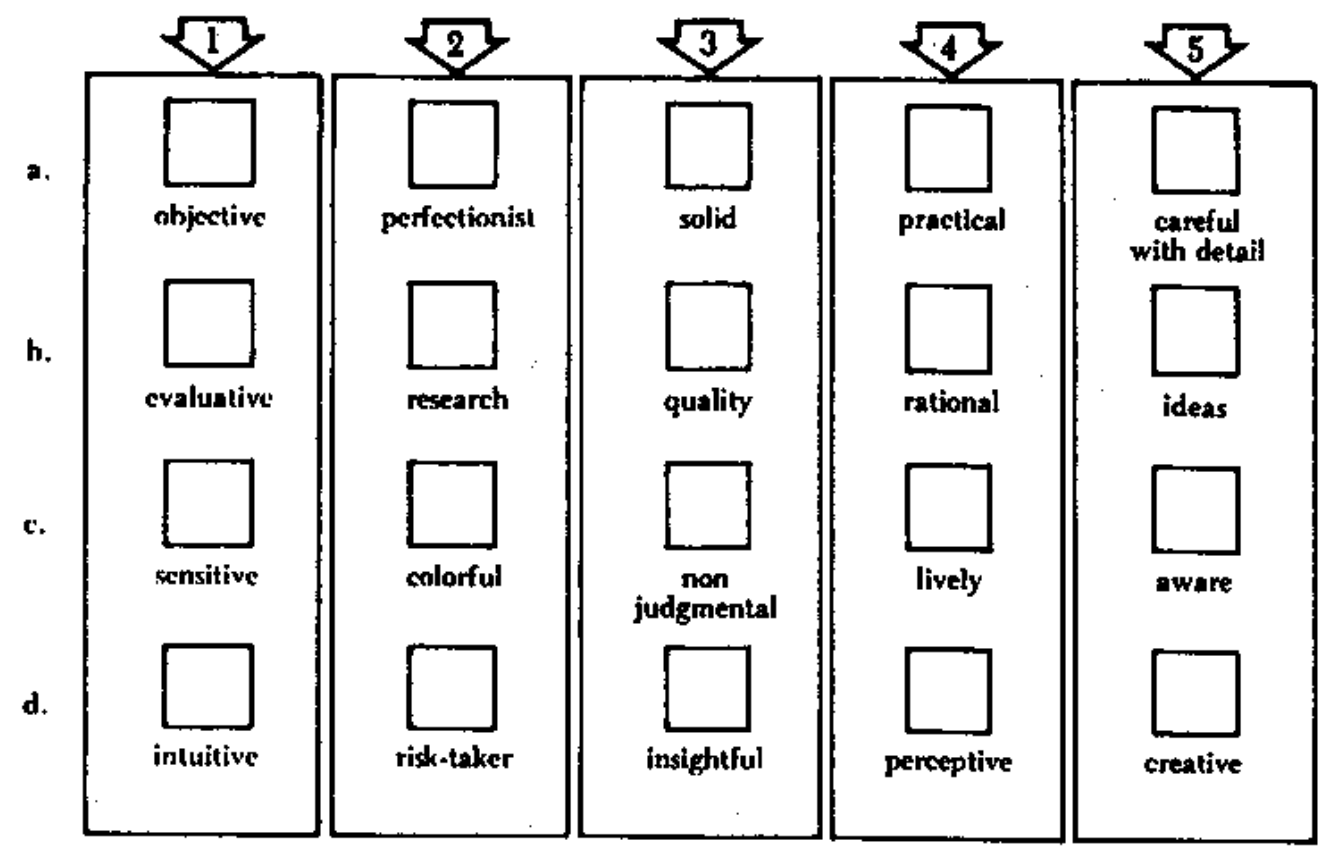

a. b. c. d.
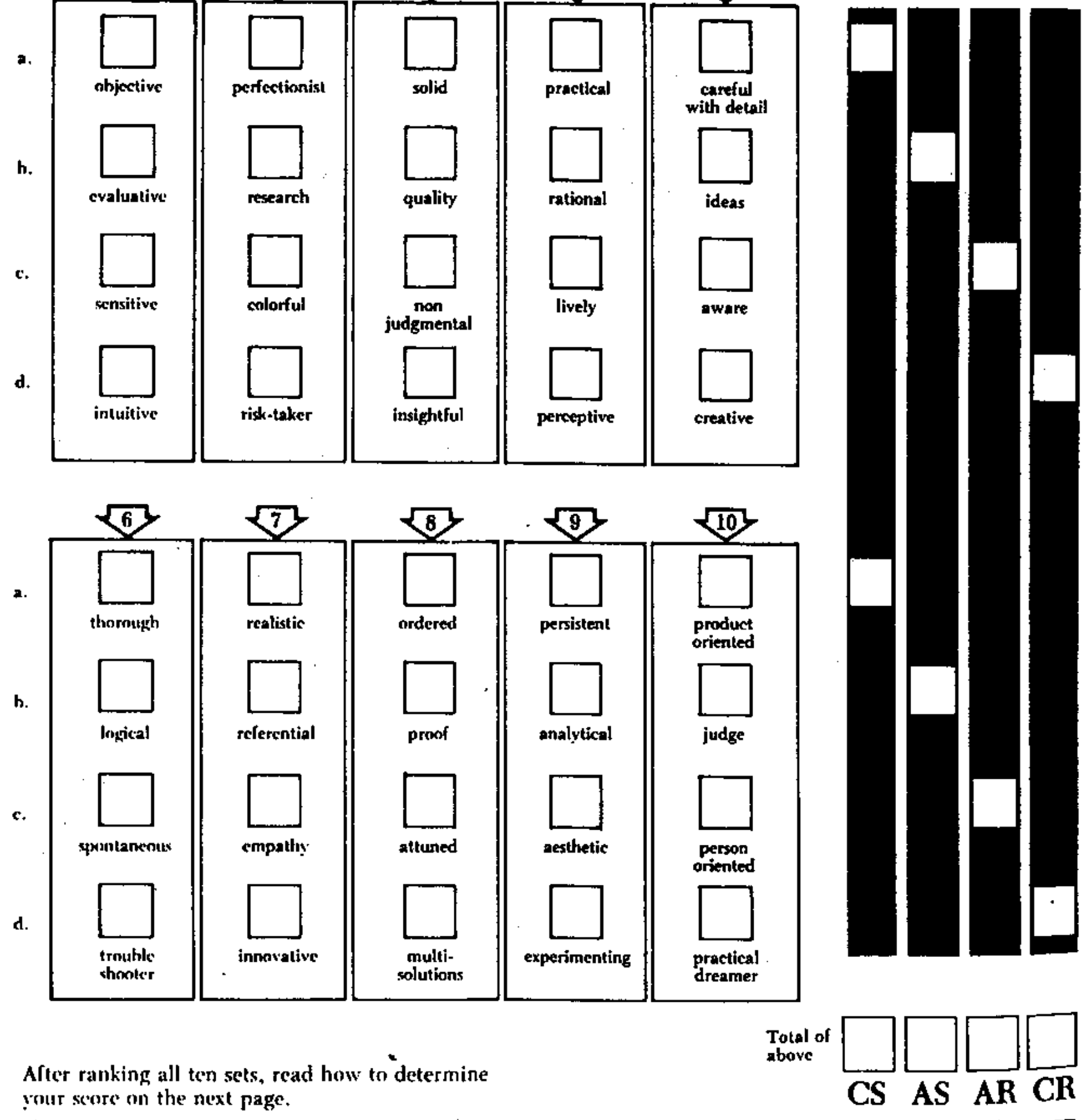


\section{SCORING}

1. Add Across. Add across the "a." row of words in the first five sets. Put that total in the top "a" column box. Do the same for the "b", "c" and "d" rows of the first set. Next, do the last group of five sets, putting the row totals in the bottom group of boxes.

\section{Example}

a. $4+4+1+3+2 \quad 14$

a. $1+3+4+2+1$

$$
\text { of above } \frac{25}{\text { CS }}
$$

2. Add Down. Add the top and bottom box in each scoring column to get the total for that column.

3. Check. If your combined total scores of CS (a), AS (b), AR (c) and CR (d) is greater or less than 100. please recheck your addition. All four columns should total exactly 100. 


\section{GRAPHING}

Use the Style Profile below to graph your scores.

1. On the vertical axis leading toward 12 o'clock (Concrete Sequential) place a large dot by the number which corresponds to your total CS (col a) score.

Example:

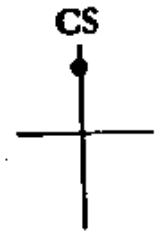

2. On the horizontal axis leading toward 3 o'clock (Abstract Se(juential), place a large dot by the number which corresponds to your total AS (col.b) score.

Example:

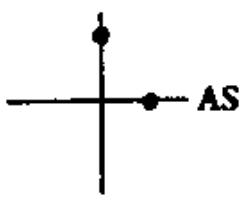

3. On the vertical axis leading toward 6 o clock (Abstract Random) place a large dot by the number which corresponds to your total AR (col.c) score.

Example:

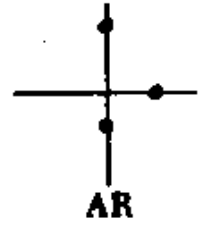

4. On the horizontal axis leading toward 9 o clock (Concrete Random) place a large dot by the number which corresponds to your total CR (ml.d) score.

Example:

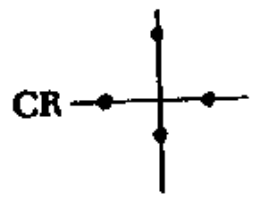

5. Now join the dots with straight lines to form a foursided figure.

Example:<smiles></smiles>

You now have a graphic representation of your dominate (27-40 points), intermediate (16-26 points) and tow (10.15 points) style, or "mediation," channels. 
APPENDIX G

PILOT SURVEY OF THE SETONWORLDWIDE FACULTY 


\section{INSTRUCTIONAL ACTIVITIES SURVEY}

My name is Thomas Butler and I am a doctoral candidate at Seton Hall. My dissertation will focus on potential relationships between learning styles and the types of instructional methods used in on-line courses. This pre-survey will aid in the development of the instrument used to survey an on-line population.

Please indicate which of the following instructional activities are used in your web course(s).

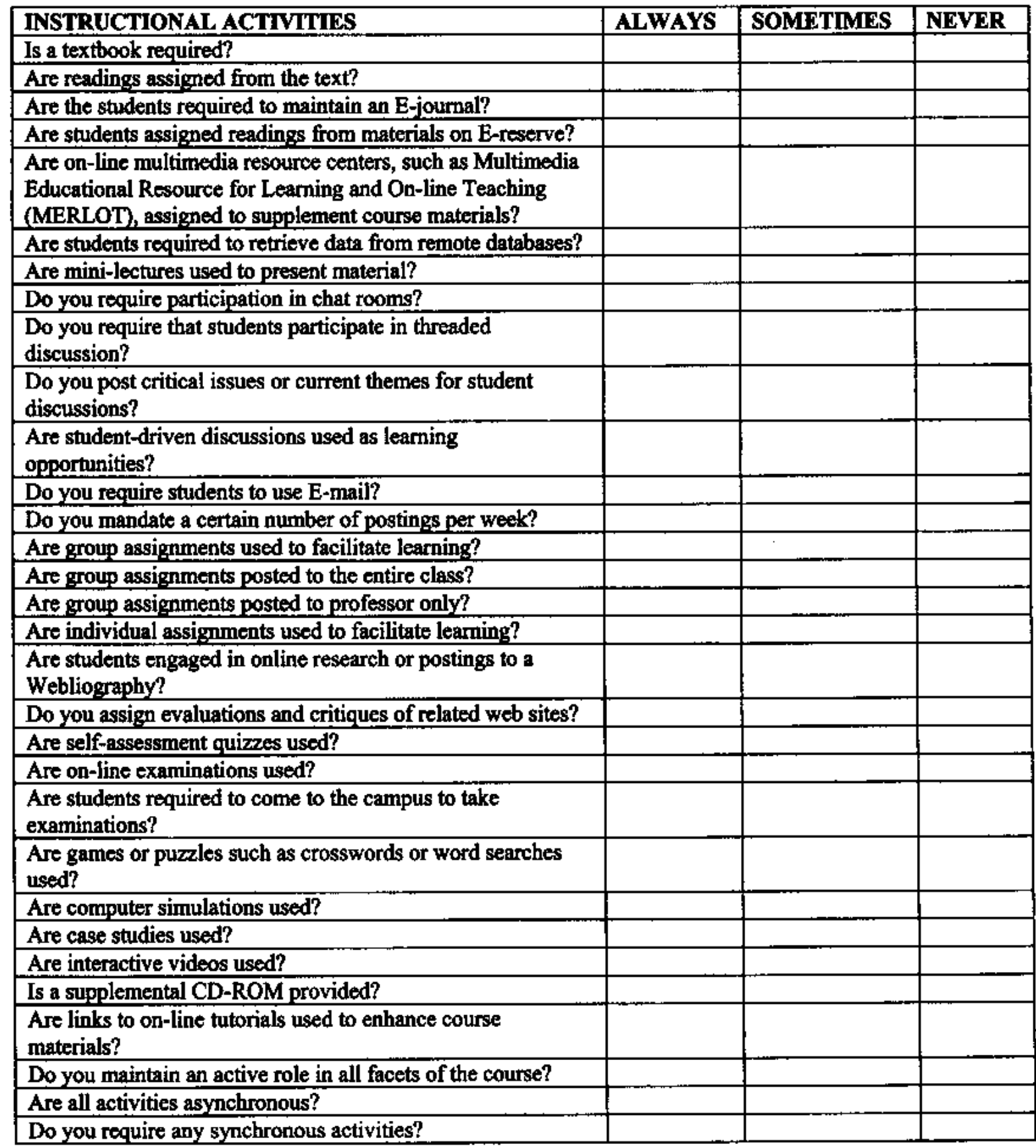


Please comment on any of the instructional activities listed and feel free to add any other activities that you use that are not listed above

Thank you for your participation! If you would like a copy of the results of this pre-survey or any aspect of my dissertation, please provide your name and e-mail. 
APPENDIX H

SAMPLE OF THE STUDENT SURVEY (PART B) 


\section{PART B}

\section{SURVEY}

\section{ABOUT YOU AND YOUR PROGRAM}

Please answer the following questions about you and your program:

1. Select the online degree program in which you are currently entolled:

Master of Arts in Counseling (MAC)

- Master of Arts in Strategic Communication and Leadership (MASCL)

- Master of Education Administration and Supervision (EDAS)

- Master of Health Care Administration

_ Master of Science in Nursing

2. Please indicate your age:

Years

Months

3. Gender:

Male

Female

4. How long have you been in your current online program?

Less than 4 months

More than 4 months

5. How many web-based courses have you taken (including this current course)?

1
-2
-3
-4
-5 or more

6. What were your reasons for taking a web-based program (select all that apply)?

Convenience

Course content

Interactive pedagogy

- Course not offered as a traditional course

_ Appeal of web-based learning

7. To date, how satisfied are you with your overall online degree program?

Satisfied

- Somewhat satisfied

- Somewhat dissatisfied

- Dissatisfied

- N/A 


\section{LOG-ON TIME}

8. Please indicate the best time for you to learn in an online course (select all that apply).

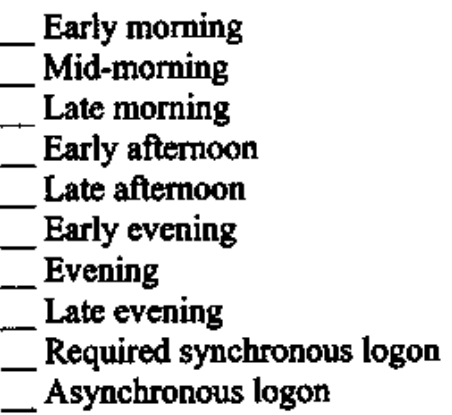

\section{INSTRUCTIONAL ACTIVITIES}

Based on your overall online learning experiences, please rate the

following learning activities which you regard are least or most

beneficial to your learning in the online environment.

9. Reading assignments from required textbooks to supplement web materials:

Least beneficial

- Somewhat beneficial

- Neutral

Beneficial

Most beneficial

10. Maintaining E-journals:

Least beneficial

Somewhat beneficial

Neutral

Beneficial

Most beneficial

11. Readings from additional materials on E-reserve:

Least beneficial

Somewhat beneficial

Neutral

Beneficial

Most beneficial

12. Referrals to multimedia resource centers to locate additional information:

Least beneficial

- Somewhat beneficial

- Neutral

- Beneficial

_ Most beneficial 
13. Retrieving data from remote data bases and other sources:

Least beneficial

Somewhat beneficial

Neutral

- Beneficial

- Most beneficial

14. Online mini-lectures:

Least beneficial

— Somewhat beneficial

- Neutral

-. Beneficial

Most beneficial

15. Dialog with fellow students in chat rooms: Least beneficial

- Somewhat beneficial

_ Neutral

- Beneficial

_ Most beneficial

16. Discussing critical issues and current trends with fellow students through instructor directed threaded discussions:

Least beneficial

Somewhat beneficial

- Neutral

Beneficial

- Most beneficial

17. E-mail as a communication medium: Least beneficial

- Somewhat beneficial

- Neutral

- Beneficial

- Most beneficial

18. Posting a mandatory number of assignments or logons per week: Least beneficial

- Somewhat beneficial

- Neutral

Beneficial

- Most beneficial

19. Group assignments and activities:

_ Least beneficial

— Somewhat beneficial

- Neutral

Beneficial

Most beneficial 
20. Individual assignments and activities:

Least beneficial

Somewhat beneficial

- Neutral

Beneficial

Most beneficial

21. Researching and posting independent web-based research to a Webliography:

Least beneficial

— Somewhat beneficial

- Neutral

Beneficial

- Most beneficial

22. Evaluating related web-sites:

Least beneficial

- Somewhat beneficial

- Neutral

- Beneficial

— Most beneficial

23. Self-assessment quizzes:

Least beneficial

- Somewhat beneficial

- Neutral

Beneficial

_ Most beneficial

24. Online examinations:

-Least beneficial

_ Somewhat beneficial

- Neutral

- Beneficial

Most beneficial

25. Computer simulations:

Least beneficial

- Somewhat beneficial

- Neutral

Beneficial

_Most beneficial

26. Case studies:

Least beneficial

- Somewhat beneficial

Neutral

-... Beneficial

Most beneficial 
27. Viewing video clips:

_ Least beneficial

— Somewhat beneficial

- Neutral

- Beneficial

_Most beneficial

28. Creating video assignments:

Least beneficial

Somewhat beneficial

- Neutral

- Beneficial

_Most beneficial

29. CD-ROMs or links to on-line tutorials:

_. Least beneficial

_ Somewhat beneficial

- Neutral

Beneficial

_ Most beneficial

30. Please indicate if there are any other online activities that you feel are beneficial to your learning:

31. Please rate the level of instructor interaction that best enhances your learning:

_ I prefer a low-degree of instructor interaction and guidance.

- I prefer a high degree of instructor interaction and guidance.

- I don't need much instructor guidance or interaction past the original instructions.

\section{THANK YOU FOR YOUR PARTICIPATIONI}

